University of Nebraska - Lincoln

DigitalCommons@University of Nebraska - Lincoln

2004

DO METEOROLOGISTS SUPPRESS THUNDERSTORMS? Radar-

Derived Statistics and the Behavior of Moist Convection

Matthew D. Parker

Jason C. Knievel

Follow this and additional works at: https://digitalcommons.unl.edu/geosciencefacpub

Part of the Earth Sciences Commons

This Article is brought to you for free and open access by the Earth and Atmospheric Sciences, Department of at DigitalCommons@University of Nebraska - Lincoln. It has been accepted for inclusion in Papers in the Earth and Atmospheric Sciences by an authorized administrator of DigitalCommons@University of Nebraska - Lincoln. 


\title{
DO METEOROLOGISTS SUPPRESS THUNDERSTORMS? Radar-Derived Statistics and the Behavior of Moist Convection
}

\author{
by Matthew D. Parker and Jason C. Knievel
}

\section{Reflectivity statistics from the WSR-88D network shed light on storms' behavior and reveal that meteorologists' hometowns probably are not the weather holes that many believe them to be.}

M ost meteorologists are acquainted with the notion of a weather hole-that is, a place that receives less exciting weather than does its surroundings. Exciting weather takes many forms, but when people use the term weather hole, they tend to mean a place that thunderstorms often barely miss, or near which approaching storms often dissipate. For this paper, that is the meaning we adopt.

In our experience, many meteorologists and lay weather enthusiasts genuinely believe that they live in weather holes, and this belief, almost without fail,

AFFILIATIONS: PARKER - Department of Geosciences, University of Nebraska-Lincoln, Lincoln, Nebraska; KNIEVEL-National Center for Atmospheric Research,* Boulder, Colorado

*The National Center for Atmospheric Research is sponsored by the National Science Foundation

CORRESPONDING AUTHOR: Dr. Matthew Parker, 214 Bessey

Hall, University of Nebraska-Lincoln, Lincoln, NE 68588-0340

E-mail: parker@updraft.unl.edu

DOI:10.1175/BAMS-86-3-34|

In final form 23 August 2004

(C)2005 American Meteorological Society seems to stem from countless hours spent gazing at displays of radar reflectivity. We have generally presumed that such people simply relish thunderstorms, are memorably disappointed whenever storms miss them, and erroneously conclude that their locations are subject to some kind of meteorologic disfavor.

The recent availability of multiple years' worth of national radar composites from the Weather Surveillance Radar-1988 Doppler (WSR-88D) network makes it possible to address objectively, if not definitively, whether meteorologists appear to live in weather holes and whether such an appearance is physical or artificial.

MOTIVATION. Although friendly hallway debate about weather holes perhaps does not constitute a pressing scientific problem, meteorologists' seemingly common belief that they live in weather holes suggests that the statistical behavior of moist convection is poorly understood. If moist convection is somewhat erratic-often dissipating, reforming, and moving nonlinearly-then an observer should expect upstream thunderstorms to strike any single location far less frequently than they strike anywhere else but that single location. To paraphrase Grazulis (2001) in his commen- 
tary on the probability of tornado strikes, "there" encompasses much more area than "here" does.

Our study is an effort to satisfy our curiosity about rumored weather holes while simultaneously testing a few simple methods of constructing climatographies of convective echoes using the comparatively new, and readily available, data from the WSR-88D network. In the future, radar-based climatographies may prove to be very powerful, important tools for forecasting thunderstorms and for quantifying the risks that thunderstorms pose to society. But, before that potential is realized, limitations in the WSR-88D network must be better documented and mitigated.

BACKGROUND. Thunderstorms are defined by their lightning and thunder, and it was upon observations of thunder that researchers based early climatographies of thunderstorms in the United States (e.g., Harrington 1894; Alexander 1915; Changery 1981; Dai 2001a,b). Before 1893, precipitation had to accompany thunder to warrant an official thunderstorm report, but this is no longer true (Humphreys 1920). In the last few decades, lightning has been used very successfully for thunderstorm climatographies, owing to the regional and national detection networks established starting in the 1980s (e.g., Reap 1986; Orville 1987; Reap and MacGorman 1989; Orville and Huffines 2001), and to satellite-borne instruments such as the Lightning Image Sensor (e.g., Christian et al. 1999) and Optical Transient Detector (e.g., Boccippio et al. 2001).

The remaining methods of identifying or, at least, inferring thunderstorms rely on clouds and precipitation as proxies for lightning and thunder. Spreading cirrus tops of anvil clouds have been used as markers in satellite-based climatographies (e.g., Banta and Schaaf 1987). Hail has also been used, but standard National Weather Service hail reports greatly underrepresent thunderstorms (Court and Griffiths 1981; Witt et al. 1998) and may be biased toward severe thunderstorms, which are distributed differently from the total population of thunderstorms (Wallace 1975). Rain, on the other hand, has proven quite useful for thunderstorm climatographies. Although rainfall alone is not a reliable discriminator among convective modes, rainfall rate can be. Rainfall rates inferred from radar reflectivity, in particular, are extremely useful for constructing climatographies of thunderstorms. Until recently, researchers relied primarily on manually logged reflectivity (e.g., Byers and Braham 1949; Falconer 1984; Michaels et al. 1987; Matthews and Geerts 1995). Now, in the United States at least, the WSR-88D network makes possible more automated regional and national studies of thunderstorm distributions through datasets that provide excellent resolution and good, if not thorough, coverage (e.g., MacKeen and Zhang 2000).

No matter the data on which they are based, virtually all climatographies reveal pronounced spatial variability in areas where thunderstorms occur. Not surprisingly, the scale of the variability follows the resolution of the data. Spatial variability consistent enough to appear in extensive climatographies must be due to fixed, slowly varying, or regularly recurring influences on moist convection. For example, mechanical lifting of conditionally unstable air by inclined ground (Hallenbeck 1922; Banta 1990) or by sea breezes (Frank et al. 1967; Pielke 1974) can concentrate moist convection. Conversely, moist convection may be infrequent over, and immediately downwind from, relatively cool lakes (Wilson 1977; Segal et al. 1997), as well as beneath subsiding branches of solenoidal circulations (Hindman 1973; Banta and Schaaf 1987). Soil moisture and vegetation also influence the location and timing of moist convection, but the complexity and nonlinearity of the processes involved make the precise results of those influences hard to predict (Pielke 2001). Moreover, compared with many physiographic influences on moist convection, soil moisture and vegetation can change quickly as, for example, irrigation and crop maturity on farms vary through the growing season (Fowler and Helvey 1974; Stidd 1975; Moore and Rojstaczer 2001).

Unquestionably, topography and land cover influence distributions of thunderstorms. Is it also possible that meteorologists and other weather enthusiasts influence distributions by suppressing or deflecting thunderstorms? Such superstition seems akin to the belief that a community is protected from tornadoes by virtue of a nearby hallowed burial site (e.g., Grazulis 2001; Sobczyk 2002). Yet meteorologists and other weather enthusiasts have insisted to us that they live in weather holes, sometimes with the zeal usually reserved for discussions of politics and sports. If such suspicions are correct, either meteorologists do influence weather or they have the astoundingly rotten luck of consistently establishing educational programs, research institutions, and forecasting companies in cities where thunderstorms just happen to be relatively infrequent. Most likely, these superstitious meteorologists simply misunderstand the statistical behavior of convection.

Henceforth, weather hole, or simply hole, means a site that receives disproportionately fewer thunderstorms than its surroundings receive; weather hot spot, or simply hot spot, means the converse. Objective definitions follow in the next section. 


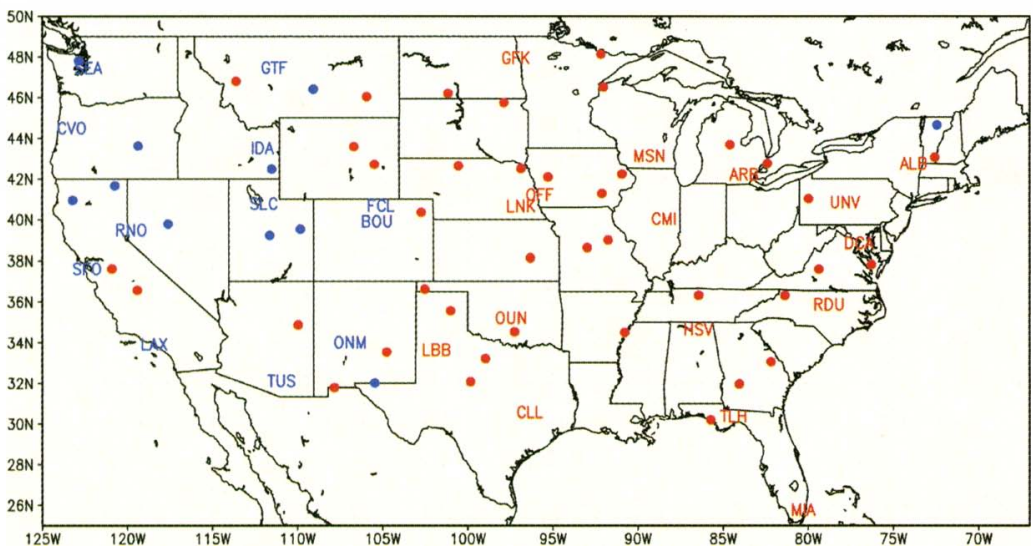

FIG. I. Target sites. Three-letter identifiers mark 28 locations with large meteorological communities, chosen for detailed study. Abbreviations are defined in Table I. Dots mark 50 randomly selected background targets. Targets with good radar coverage are marked in red; the rest are marked in blue.

DATA AND METHODS. Radar. Because, judging from our experience, meteorologists first begin suspecting that they live in weather holes while gazing with growing consternation at approaching and dissipating or deviating thunderstorms on plan-position indicator (PPI) radar displays, radar reflectivity seemed to be the most appropriate dataset for this research.

Our analyses incorporate NOWrad ${ }^{\text {mot }}$ national composites, or summaries, of WSR-88D reflectivity data for 6 years: $1996-$ 2000 and 2002. We omitted data from 2001 because they were missing for 1 January to 3 May. NOWrad ${ }^{\text {tw }}$ composites are products of the Weather Systems International (WSI) Corporation. To create the composites, raw data on a polar grid of $1^{\circ} \times 1 \mathrm{~km}$ from each radar are converted to a Cartesian grid with nominal temporal, spatial, and reflectivity intervals of 15 $\min , 2 \mathrm{~km} \times 2 \mathrm{~km}$, and $5 \mathrm{dBZ}$. Each pixel's value is the largest reflectivity measured in a 15-min interval by any radar in a column above a point, with the exception that reflectivity from radars within $230 \mathrm{~km}$ of a point is given priority over reflectivity from radars beyond $230 \mathrm{~km}$. Near the center of the raw polar grid, where over- sampling occurs during conversion to the Cartesian grid, the largest reflectivity is used. When a cone of silence above a radar is not filled by reflectivity from another radar within $230 \mathrm{~km}$, extended-range reflectivity from the nearest radars is used. Automated computer algorithms at WSI filter bad data from individual WSR-88Ds and from the national composite before a radar meteorologist removes by hand most remaining artifacts, including anomolous propogation echoes. NOWrad ${ }^{\text {tw }}$ data cover most of the conterminous United States.

For the purposes of commentary in this article, we henceforth call each echo that is $\geq 40 \mathrm{dBZ}$ a storm element (or, more briefly, a storm) and call each 15-min radar summary a time. Other researchers have used the same or similar thresholds to diagnose thunderstorms and to discriminate between convective and

\begin{tabular}{|ll|ll|}
\hline \multicolumn{4}{|c|}{$\begin{array}{l}\text { TABLE } \\
\text { of their prominent populations of } \\
\text { distribution across the conterminous }\end{array}$ United States. } \\
\hline ID & Location & ID & Location \\
\hline ALB & Albany, NY & LNK & Lincoln, NE \\
\hline ARB & Ann Arbor, MI & MIA & Miami, FL \\
\hline BOU & Boulder, CO & MSN & Madison, WI \\
\hline CLL & College Station, TX & OFF & Bellevue, NE \\
\hline CMI & Urbana-Champaign, IL & ONM & Socorro, NM \\
\hline CVO & Corvalis, OR & OUN & Norman, OK \\
\hline DCA & Washington, DC & RDU & Raleigh-Durham, NC \\
\hline FCL & Fort Collins, CO & RNO & Reno, NV \\
\hline GFK & Grand Forks, ND & SEA & Seattle, WA \\
\hline GTF & Great Falls, MT & SFO & San Francisco, CA \\
\hline HSV & Huntsville, AL & SLC & Salt Lake City, UT \\
\hline IDA & Idaho Falls, ID & TLH & Tallahassee, FL \\
\hline LAX & Los Angeles, CA & TUS & Tucson, AZ \\
\hline LBB & Lubbock, TX & UNV & State College, PA \\
\hline
\end{tabular}


stratiform rain (e.g., Gamache and Houze 1982; Falconer 1984; Rickenbach and Rutledge 1998). Even so, the discrimination is imperfect because bright bands in regions of melting stratiform precipitation can produce reflectivities $\geq 40 \mathrm{dBZ}$. However, the extent to which this caused us to overcount thunderstorms is debatable; for example, the commonly observed bright bands within stratiform regions of mesoscale convective systems (MCSs; Biggerstaff and Houze 1993) are often attended by lightning and thunder, which define a thunderstorm. Cold-season stratiform precipitation may also produce bright banding. However, we found that almost all of the echoes $\geq 40 \mathrm{dBZ}$ in our sample actually occurred during the warm season (MarchOctober), so this appears to have had little effect on our results.

The appendix provides some additional commentary on the limitations of the NOWrad ${ }^{\text {me }}$ dataset and their possible impacts upon our study.

Targets. To test for weather holes and hot spots, we chose 28 target cities with notable meteorological communities (Fig. 1). Table 1 defines their abbreviations. The pairs of LNK-OFF and BOU-FCL were included to examine spatial variability in storms where the authors reside. Reassuringly, despite some limitations in the radar dataset, these sites revealed basic regional consistency in the statistics that we used. To create a background population of targets we used a random number generator to determine 50 latitudelongitude pairs within the conterminous United States (dots in Fig. 1). The 50 random points were useful because it was not computationally feasible to compute all of the statistics for every point within the radar network.

Largely owing to terrain (Fig. 2), radar coverage was incomplete at some of the targets. Therefore, we isolated from the 78 total targets a subset of targets with good radar coverage (comprising 55 targets of 16 meteorological cities and 39 random points, shown with red in Fig. 1). In making these selections, we subjectively defined "good coverage" to mean that fields of the statistics we explain in the next subsection did not exhibit any excessive abnormalities due to blocking by terrain, miscalibration, or unusually sparse distributions of radars in the network.

Statistics. Most of our analyses are based on statistics calculated from radar data over the conterminous United States and over several areas, centered on the middle of each target city. Many statistics were averaged over a circle with a $100-\mathrm{km}$ radius. We also considered three square arrays representing familiar geo- political areas. A square that is $274 \mathrm{~km} \times 274 \mathrm{~km}$ $\left(75076 \mathrm{~km}^{2}\right)$ approximates the size of a typical National Weather Service county warning area (CWA). A square that is $54 \mathrm{~km} \times 54 \mathrm{~km}\left(2916 \mathrm{~km}^{2}\right)$ approximates the size of a typical county in the United States. A square that is $14 \mathrm{~km} \times 14 \mathrm{~km}\left(196 \mathrm{~km}^{2}\right)$ approximates the size of a moderately large city. This last target array, the innermost of the three, is the smallest area for which statistics were calculated. Points within the square arrays are identified by their locations relative to a target pixel, which has coordinates of $x=0, y=0$.

Our statistics are calculated from several formulas. First, for the binary "storm" variable $i_{40}$, defined by

$$
i_{40}=\left\{\begin{array}{l}
1 \\
0 \text { when } \begin{array}{l}
\mathrm{dB} Z \geq 40 \\
\mathrm{~dB} Z<40
\end{array}
\end{array}\right.
$$

we computed the following statistics at each point in the target array for the $n$ times in the 6-yr sample as follows:

$$
\operatorname{Pr}_{\text {storm }}(x, y)=\frac{1}{n} \sum_{t=1}^{n} i_{40}(x, y, t) \text {, }
$$

which is the probability, or frequency (Wilks 1995), that point $(x, y)$ had a storm at a randomly selected time, and

$$
\begin{aligned}
& \operatorname{Pr}_{\text {hit storm }}(x, y, \Delta t) \\
& =\frac{\sum_{t=1}^{n} i_{40}(x, y, t) \times i_{40}(0,0, t+\Delta t)}{\sum_{t=1}^{n} i_{40}(x, y, t)},
\end{aligned}
$$

which is the normalized probability that, when a storm at point $(x, y)$ occurred, a storm at the target also occurred $\Delta t$ later, wherein $\Delta t$, the lag time, is taken in 15-min intervals between 0 and $120 \mathrm{~min}$. Hereafter, $\operatorname{Pr}_{\text {hitstorm }}(x, y, \Delta t=0)$ is designated $\operatorname{Pr}_{\text {coexistencelstorm }}(x, y)$ and represents the probability that storms simultaneously existed at some regional point and at the target. In order to summarize all of the information represented by the two-dimensional $\mathrm{Pr}_{\text {hit|storm }}$ field for all other lag times, we computed the overall probability that a storm at point $(x, y)$ was followed by a storm at the target at any time during the subsequent $2 \mathrm{~h}$ : 


$$
\begin{aligned}
\operatorname{Pr}_{\text {anyhit|storm }}(x, y)= & 1-\left\{\left[1-\operatorname{Pr}_{\text {hit|storm }}(x, y, \Delta t=15 \mathrm{~min})\right]\right. \\
& \left.\times\left[1-\operatorname{Pr}_{\text {hit|storm }}(x, y, \Delta t=30 \mathrm{~min})\right][\ldots]\left[1-\operatorname{Pr}_{\text {hit } \mid s t o r m}(x, y, \Delta t=120 \mathrm{~min})\right]\right\}
\end{aligned}
$$

Finally, we also analyzed the time-lagged reflectivity correlation between $\mathrm{dBZ}(x, y, t)$ and $\mathrm{dBZ}(0,0, t+\Delta t)$, wherein $\Delta t$ was again taken in 15 -min intervals between 15 and $120 \mathrm{~min}$. Because the lagged correlations in $\mathrm{dB} Z$ essentially confirmed the results from our analyses of $\operatorname{Pr}_{\text {hit|storm }}$, we mention them only briefly in this article.

Statistical definitions of a weather hole and hot spot. We consider a weather hole to satisfy two primary criteria: it must have had markedly fewer storms than did its surroundings, and it must have been disproportionately missed by approaching storms. A hot spot satisfies the converse criteria.

The first criterion - whether a target had markedly fewer or more storms than did its surroundings-is quantified by $\mathrm{Pr}_{\text {storm }}$. We computed $\mathrm{Pr}_{\text {storm }}$ for each target and for each pixel in its surrounding county and CWA. We then computed the following fractional differences in each target's $\mathrm{Pr}_{\text {storm: }}$ ( city - CWA)/CWA and (county - CWA)/CWA. If a good target fell within the bottom quartile of the distribution of all 55 good targets for either fractional difference, it was deemed a potential weather hole. The converse defines a potential hot spot. (We use the qualifier potential because the complete definitions of a hole and hot spot are based on more than just a single criterion.) Figure 3 summarizes the distributions of targets' $\mathrm{Pr}_{\text {storm }}$ and fractional differences thereof.

The second criterion, whether a target was disproportionately missed by approaching storms, is quantified by $\mathrm{Pr}_{\text {anyhitstorm }}$. We computed an average $\mathrm{Pr}_{\text {anyhit|storm }}$ within a radius of $100 \mathrm{~km}$ at each of the 55 good targets. If a target's average value of $\mathrm{Pr}_{\text {anyhit|storm }}$ fell within the bottom or top quartile of the distribution for good targets, the target was considered a potential hole or hot spot, respectively. Figure 4a summarizes the distribution of targets' $\mathrm{Pr}_{\text {anyhitstorm }}$.

Both criteria were necessary because sites with low (or high) values of $\mathrm{Pr}_{\text {storm }}$ were not necessarily holes (or hot spots). Many sites with very low $\operatorname{Pr}_{\text {storm }}$ are simply located within regions where storms are unusually scarce compared to elsewhere in the nation. These may be dull places for a meteorologist to live, but they are not "missed" by storms on the regional scale in any recurring way.

Because our objective definitions of holes and hot spots are somewhat arbitrary, and because the behavior of convection is apparently not well understood, we analyzed a few additional parameters based on the statistics above in order to paint a richer picture of the patterns of thunderstorms in the vicinity of the targets. The first parameter-an average of the maximum lagged correlations in $\mathrm{dBZ}$ (for any lag, $\Delta t=15$ $120 \mathrm{~min}$ ) for each pixel within $100 \mathrm{~km}$ of a targetmeasures how well preceding regional reflectivities were correlated with a target's reflectivity (summarized in Fig. 4b). This parameter was less susceptible to any possible local biases associated with radar calibration and coverage but was somewhat redundant with

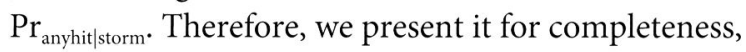
but generally without comment. The second parameter is a fraction, wherein the number of storms arriving from within $60^{\circ}$ of the most common upstream azimuth is divided by the total number of storms to hit a target (summarized in Fig. 4c). This parameter measures the directionality of storms' paths to a target; values range from 0.33 for isotropic storm arrivals to 1.0 for unidirectional arrivals. The third and fourth pa-

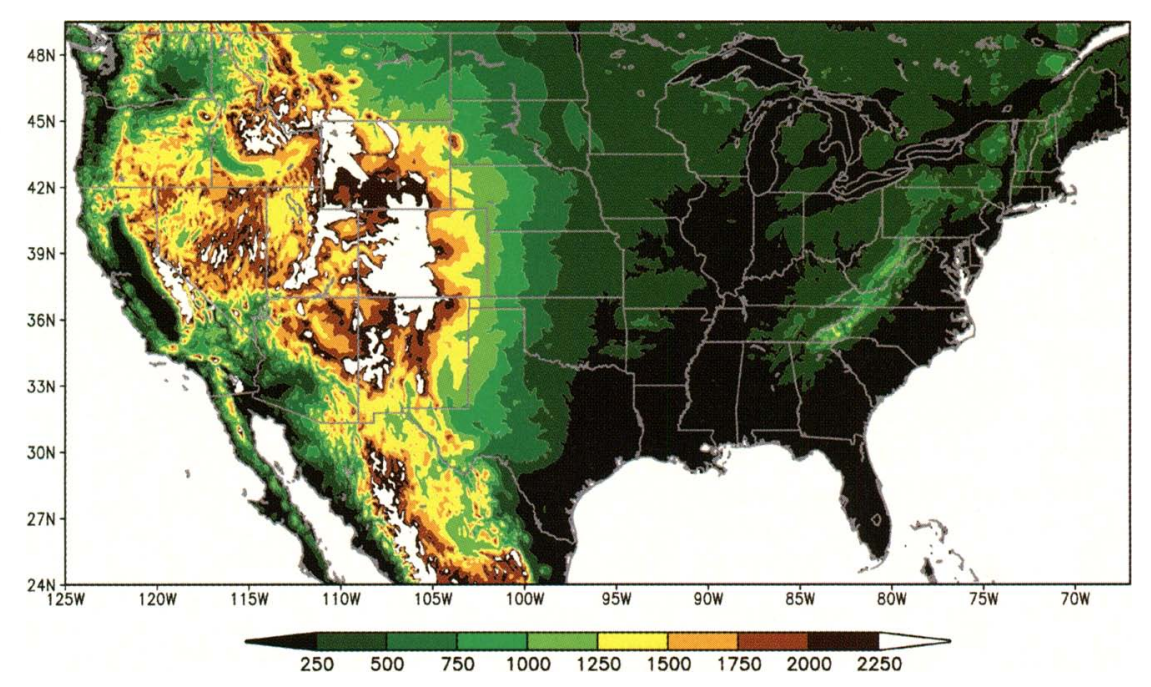

FIG. 2. Elevation ( $\mathrm{m}$ ) of topography in the conterminous United States. 
(a)

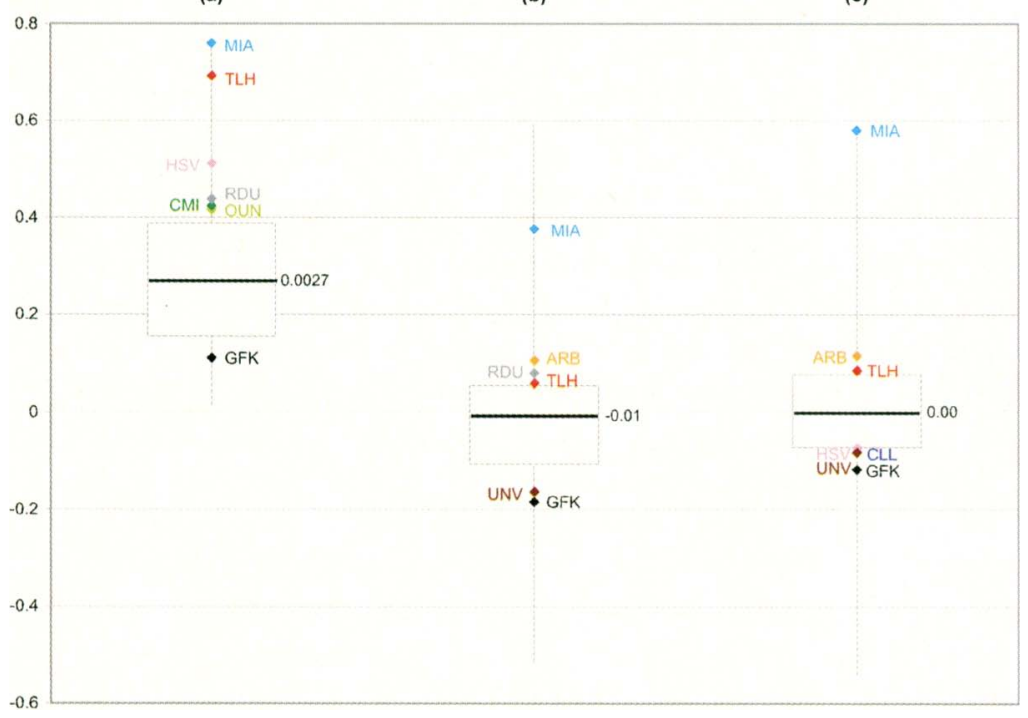

FIG. 3. Box-and-whiskers plots of statistical parameters for the good targets. The boxes bound the middle two quartiles of the population, with the median shown as a dark line. The whiskers span the top and bottom quartiles. (a) The target city's average $\mathrm{Pr}_{\text {storm; }}$ (b) the target city's fractional difference in $\mathrm{Pr}_{\text {storm }}$ ( (city-CWA)/CWA; and (c) the target county's fractional difference in $\mathrm{Pr}_{\text {storm }}$ : (county-CWA)/CWA. Values in (a) are multiplied by 100 to match the ordinates of (b) and (c). All meteorological targets that fall outside the middle two quartiles are labeled.

(a)

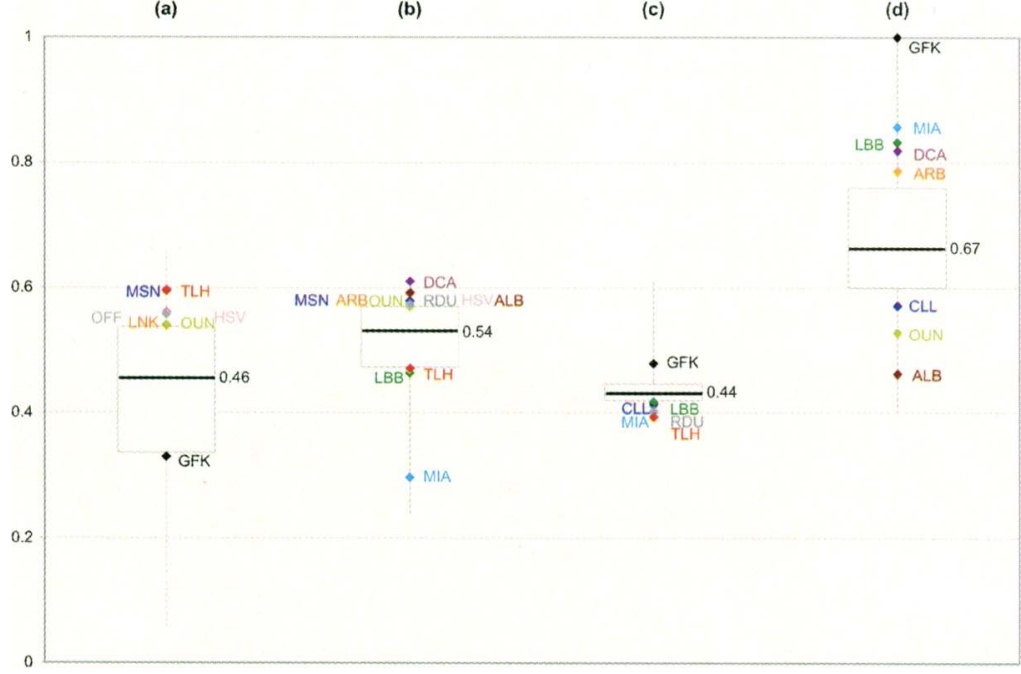

FIG. 4. Box-and-whiskers plots of statistical parameters for the good targets. The meanings of the boxes and whiskers are as in Fig. 3. (a) The average $\mathbf{P r}_{\text {anyhit|storm }}$ within a radius of $100 \mathrm{~km}$ at each target; (b) the average of the maximum lagged correlation in $\mathrm{dBZ}$ for each pixel within $100 \mathrm{~km}$ of a target; (c) the directionality of $\mathrm{Pr}_{\text {anyhit|storm }}$, a fraction wherein the number of storms arriving from within $60^{\circ}$ of the most common upstream azimuth is divided by the total number of storms to hit a target; and (d) the aspect ratio (minor axis divided by major axis) of the region circumscribed by the $\mathbf{0}$. I contour in $\mathbf{P r}_{\text {c }}$ logical targets that fall outside the middle two quartiles are labeled. rameters are the aspect ratio (minor axis divided by major axis; Fig. 4d) and area of the region circumscribed by $\operatorname{Pr}_{\text {coexistence|storm }} \geq 0.1$ (summarized in Fig. 5a). These two parameters respectively describe the relative circularity and the size of regions of storminess at a target. Finally, the fifth parameter is the area circumscribed by $\operatorname{Pr}_{\text {anyhit|storm }} \geq 0.50$, which is the footprint of the region where storms were more likely than not to be followed by a storm at a target within $2 \mathrm{~h}$ (summarized in Fig. 5b). This area $\left(\mathrm{Pr}_{\text {anyhit|storm }} \geq 0.50\right)$ was highly correlated with the $100-\mathrm{km}$ mean $\operatorname{Pr}_{\text {anyhit/storm }}$ (a correlation of 0.95 ), but is included to help orient the reader, though without much additional comment.

\section{STATISTICAL RESULTS.}

National storm frequency. Storms, as we have defined them, were most frequent in the eastern half of the country, particularly in the Southeast (Fig. 6). This distribution is grossly similar to the distributions of daily thunderstorm frequency found by Court and Griffiths (1981), and to the distribution of the mean annual density of lightning flashes found by Orville and Huffines (2001). Mesoscale structures, including distinct maxima and minima, are clearly visible in Fig. 6. Of course, some of the structures are obviously artificial, such as the high reflectivities that surrounded Wilmington, North Carolina (at $34^{\circ} \mathrm{N}, 78^{\circ} \mathrm{W}$ ), and the beam blocking by terrain in southern Arizona and New Mexico. In the appendix we comment further on such artifacts and their effect on studies such as this one.

A typical target. Because it was a typical target and not a hole or a hot spot, LNK serves to demonstrate the diagnostic capabilities of our statistics. LNK was neither a local minimum nor a significant local maximum in $\operatorname{Pr}_{\text {storm }}$ (Fig. 7a). LNK's average $\operatorname{Pr}_{\text {storm }}$ was $0.332 \times 10^{-2}$, which was $5.4 \%$ 
higher than that of its surrounding CWA. Both values placed LNK firmly in the middle of the distribution of good targets (Fig. 3).

The predominant gradient in $\mathrm{Pr}_{\text {storm }}$ from northwest to southeast (Fig. 7a) indicates that thunderstorms were slightly more common in the southeastern part of LNK's CWA than in its northwestern part. During the six years studied, storms within $100 \mathrm{~km}$ to the westnorthwest, west, and west-southwest of LNK were followed within $2 \mathrm{~h}$ by a storm at LNK at least $60 \%$ of the time (Fig. 7b), which puts LNK just barely into the top quartile in terms of $\mathrm{Pr}_{\text {anyhitstorm }}$ (Fig. 4a). However, regional reflectivity was not particularly well (nor poorly) correlated with subsequent reflectivity at LNK (Fig. 4b; LNK's value was 0.55 ).

Judging from the LNK CWA's $\mathrm{Pr}_{\text {anyhitstorm }}$ (shading in Fig. 7b), thunderstorms arrived at LNK most frequently from the west and westsouthwest, and very rarely from the southeast, although storm directionality at LNK was not extreme (Fig. 4c; LNK's value was 0.42 ). The aspect ratio of storms (Fig 4d; LNK's value was 0.71 ) and the orientation of the major axis in $\mathrm{Pr}_{\text {coexistence|storm }}$ (contours in Fig. 7b) suggest the recurrence of frontal convective bands and/or MCSs, which most frequently are oriented southwest-northeast.

Population-wide behavior. Among all 78 targets, each year the average site experienced a storm during 81 $(0.23 \%)$ of the 15 -min periods we analyzed, amounting to about $20 \mathrm{~h}$ of annual storminess. The median good target experienced about $24 \mathrm{~h}$ ( $0.27 \%)$ of storminess (Fig. 3a). The average for all pixels in the entire U.S. radar network (Fig. 6) was between these two sample averages $(0.26 \%$, or about $23 \mathrm{~h}$ of storminess). We have not provided plots of the spatial distribution of average $\mathrm{Pr}_{\text {storm }}$ for the subsample populations because they are nearly homogeneous. Most target cities were fairly similar to their surroundings, as can be seen from the fairly narrow distributions of fractional differences, grouped around 0 in Figs. 3b,c.

Plots of average $\operatorname{Pr}_{\text {anyhitstorm }}$ for all 78 targets (Fig. 8a), and for the good targets only (Fig. 8b), reveal similar structures (with similar interpretations) to those observed at LNK. As targets with poor radar coverage were eliminated from the study, values of $\mathrm{Pr}_{\text {anyhitstorm }}$ increased slightly (Fig. 8). The typical good target had a $100-\mathrm{km}$ mean $\mathrm{Pr}_{\text {anyhitstorm }}$ of 0.46 (Fig. 4a), meaning that

(a)

(b)

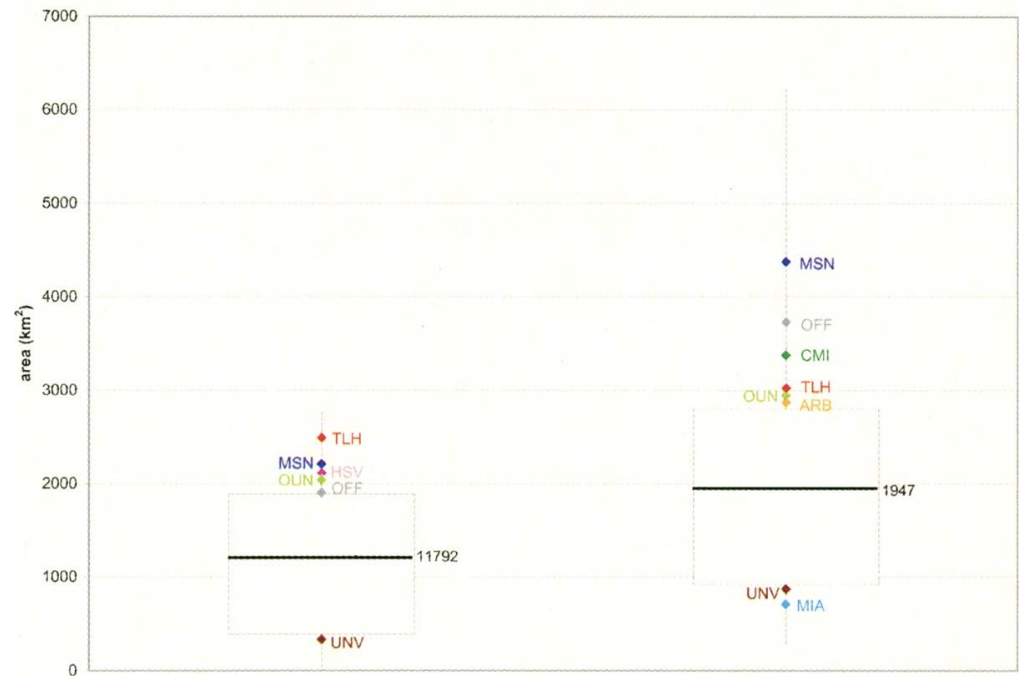

FIG. 5. Box-and-whiskers plots of statistical parameters for the good targets. The meanings of the boxes and whiskers are as in Fig. 3. (a) The area of the region in which $\mathrm{Pr}_{\text {anyhit|storm }} \geq 0.50$ and (b) the area of the region in which $\mathrm{Pr}_{\text {coexistence|storm }} \geq 0.10$. Values in (a) are divided by 10 to match the ordinate of (b). All meteorological targets that fall outside the middle two quartiles are labeled.

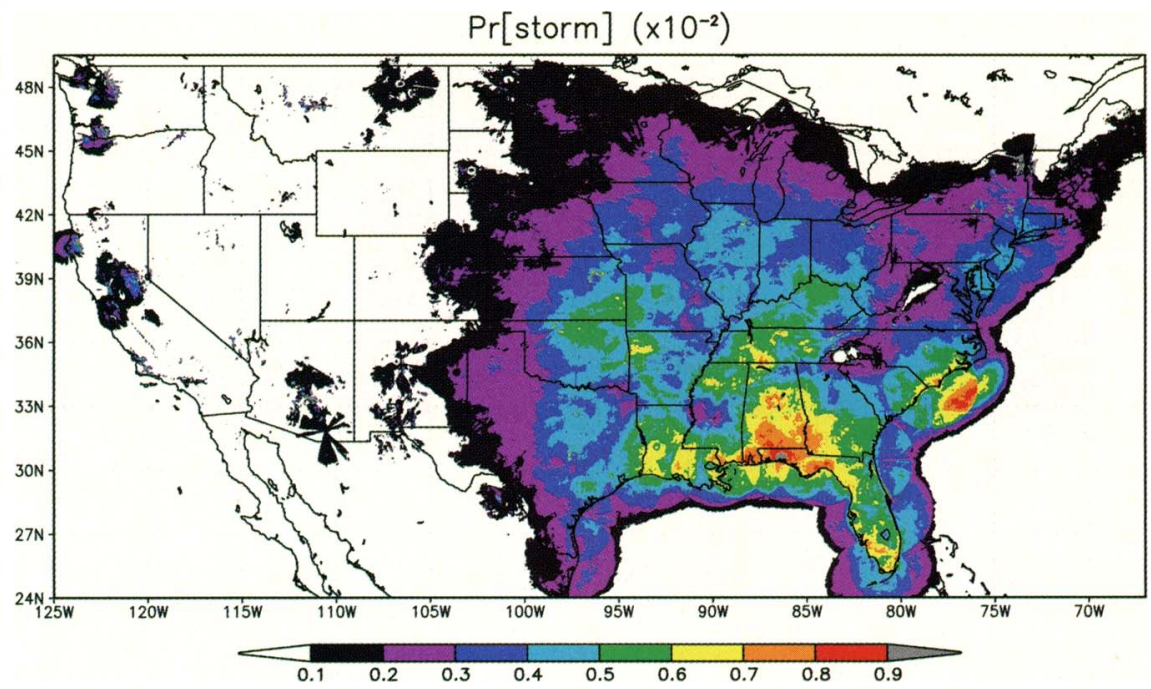

FIG. 6. Storm frequency, $\mathbf{P r}_{\text {storm }}$, over the conterminous United States. Values have been multiplied by 100 (and therefore are equivalent to percentages). The mean value for all points within the radar network is $0.258 \times 10^{-2}$. 

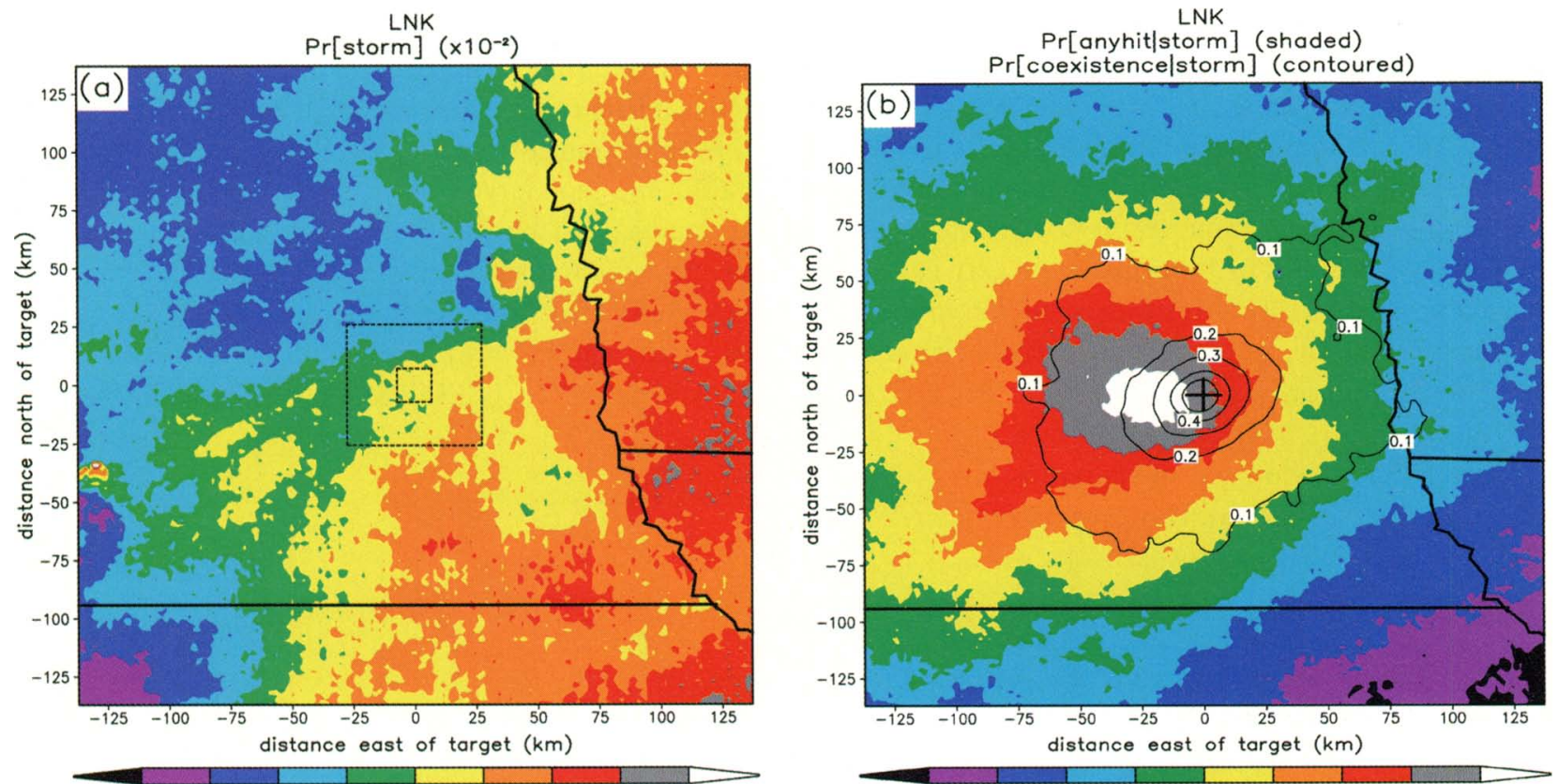

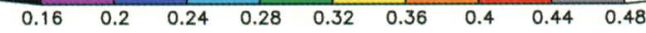

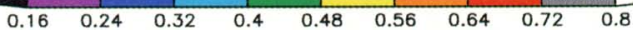

FIG. 7. Plan views of (a) $\mathbf{P r}_{\text {storm }}$ (plotted values have been multiplied by 100 and therefore are equivalent to percentages and (b) $\mathrm{Pr}_{\text {anyhit|storm }}$ (shaded) and $\mathrm{Pr}_{\text {coexistence|storm }}$ (thin contours) for LNK during the 6 yr studied. LNK is in the center of each diagram $(x=0, y=0)$. Dark contours are state boundaries. In (a) the smallest box outlines LNK's "city," and the larger box outlines LNK's "county." The full plots encompass LNK's "CWA." The statistical computations are explained in the text. The mean areal values of $\mathrm{Pr}_{\text {storm }}$ were as follows: city, $0.332 \times 10^{-2}$; county, $0.318 \times 10^{-2}$; and $\mathrm{CWA}$ $0.315 \times 10^{-2}$. The $100-\mathbf{k m}$ average $\mathrm{Pr}_{\text {anyhit|storm }}$ value was 0.54 .
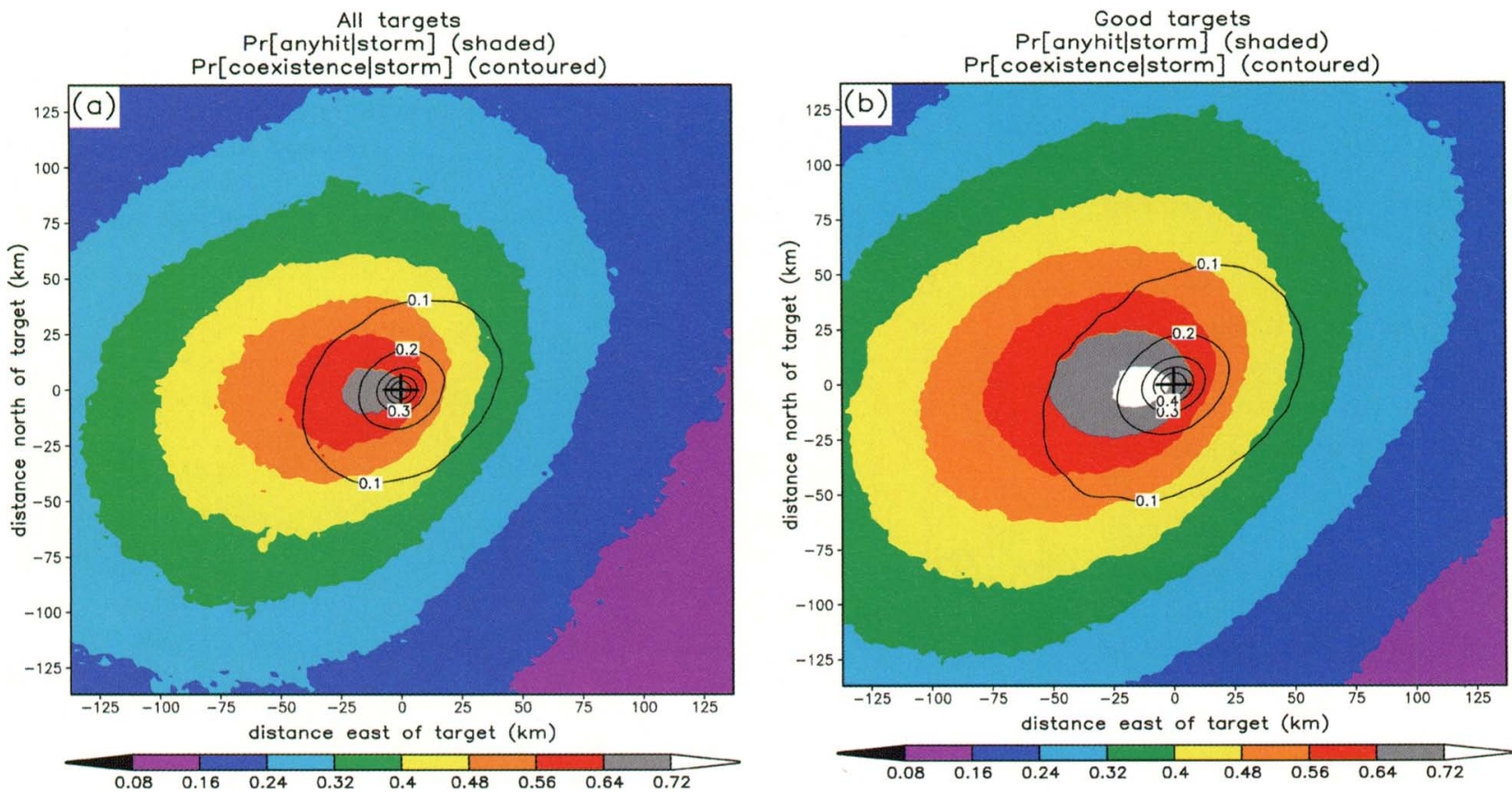

FIG. 8. Same as in Fig. 7b, except for (a) all 78 targets and (b) the 55 good targets. Note that the shading scales differ from those in Fig. 7b. The $100-\mathrm{km}$ average $\mathrm{Pr}_{\text {anyhit|storm }}$ was (a) 0.38 for all targets and (b) 0.45 for good targets.

when storms were within $100 \mathrm{~km}$ of some point, a storm followed within $2 \mathrm{~h}$ at that point slightly less than half of the time. Alternately, for the typical good tar- get, regional storms were more likely than not to hit the target when within a $11,792 \mathrm{~km}^{2}$ area nearby and upstream (Fig. 5a). 
Values both for lagged correlation in $\mathrm{dBZ}$ and for the "directionality" of $\mathrm{Pr}_{\text {anyhitstorm }}$ had narrow distributions (Figs. $4 \mathrm{~b}, \mathrm{c}$ ), suggesting that most targets' precipitation followed regional precipitation in a fairly standard way and that in most places, storms arrived from the most climatically favored $120^{\circ}$ sector roughly $45 \%$ of the time. However, there is great variety in storm aspect ratios among the good targets (Fig. 4d). The footprints of storms, or of groups of storms, were typically somewhat elongated, presumably because synoptic fronts and linear convective systems often shaped the distribution of storms in much of the United States. However, there are several targets whose local storminess appears to have been quasi circular (Fig. 4d). Notably, the storm aspect ratio was very poorly correlated with all of the other statistics that we computed. Therefore, even though aspect ratio provides useful information about typical convective behavior in a region, it does not appear to have greatly influenced either $\mathrm{Pr}_{\text {storm }}$ or $\mathrm{Pr}_{\text {anyhit|storm }}$ for the targets in this study. Interestingly, however, the directionality of $\mathrm{Pr}_{\text {anyhitstorm }}$ was moderately negatively correlated with the $100-\mathrm{km}$ mean $\mathrm{Pr}_{\text {anyhit|storm }}$ (a correlation of -0.63). In other words, targets may appear to have been weather holes if most of their storms arrived from one preferred direction, because those targets were often missed by storms that did not approach from the climatically upstream direction.

The median storm area parameter $(\mathrm{Pr}$ $\geq 0.1$ ) is $1947 \mathrm{~km}^{2}$ (Fig. 5b). This value is not meant to be taken as a literal storm size since it is an amalgam of large and small, linear, and circular storm elements over a long period of time. However, it is useful as a means of comparing targets: smaller values represent the existence of comparatively fewer large convective systems in a target's vicinity. This parameter, in turn, was strongly correlated with the $100-\mathrm{km}$ mean $\mathrm{Pr}_{\text {anyhitststorm }}$ (a correlation of 0.87 ) and with the area of $\mathrm{Pr}_{\text {anyhitststorm }} \geq 0.5$ (a correlation of 0.92 ). In other words, regions with fewer large convective systems were more often missed by regional storms (see, e.g., TLH, MSN, OUN, OFF, and UNV in Fig. 5).

Taken together, the parameters in Figs. 4 and 5 are quite useful for characterizing the regional behavior of storms. For example, MIA, although neither a hole nor a hot spot, was characterized by comparatively small (Fig. 5b), circular (Fig. 4d) storms, which arrived from all directions (Fig. 4c), rendering a very low lagged correlation in $\mathrm{dBZ}$ (Fig. 4b). Nevertheless, MIA's city mean $\mathrm{Pr}_{\text {storm }}$ was the highest in the study (Fig. 3). The picture is that of frequent and seemingly disorganized small thunderstorms.
A weather hole. The lone weather hole among the 28 meteorological targets was GFK (Fig. 9). In GFK's CWA, the regional $\mathrm{Pr}_{\text {storm }}$ decreased from south to north (Fig. 9a). Although it may not be obvious at first glance that GFK's local Pr $_{\text {storm }}$ was significantly lower than that of the surrounding CWA, Fig. 9a does reveal that GFK resides within a corridor where $\mathrm{Pr}_{\text {storm }}$ was low com-
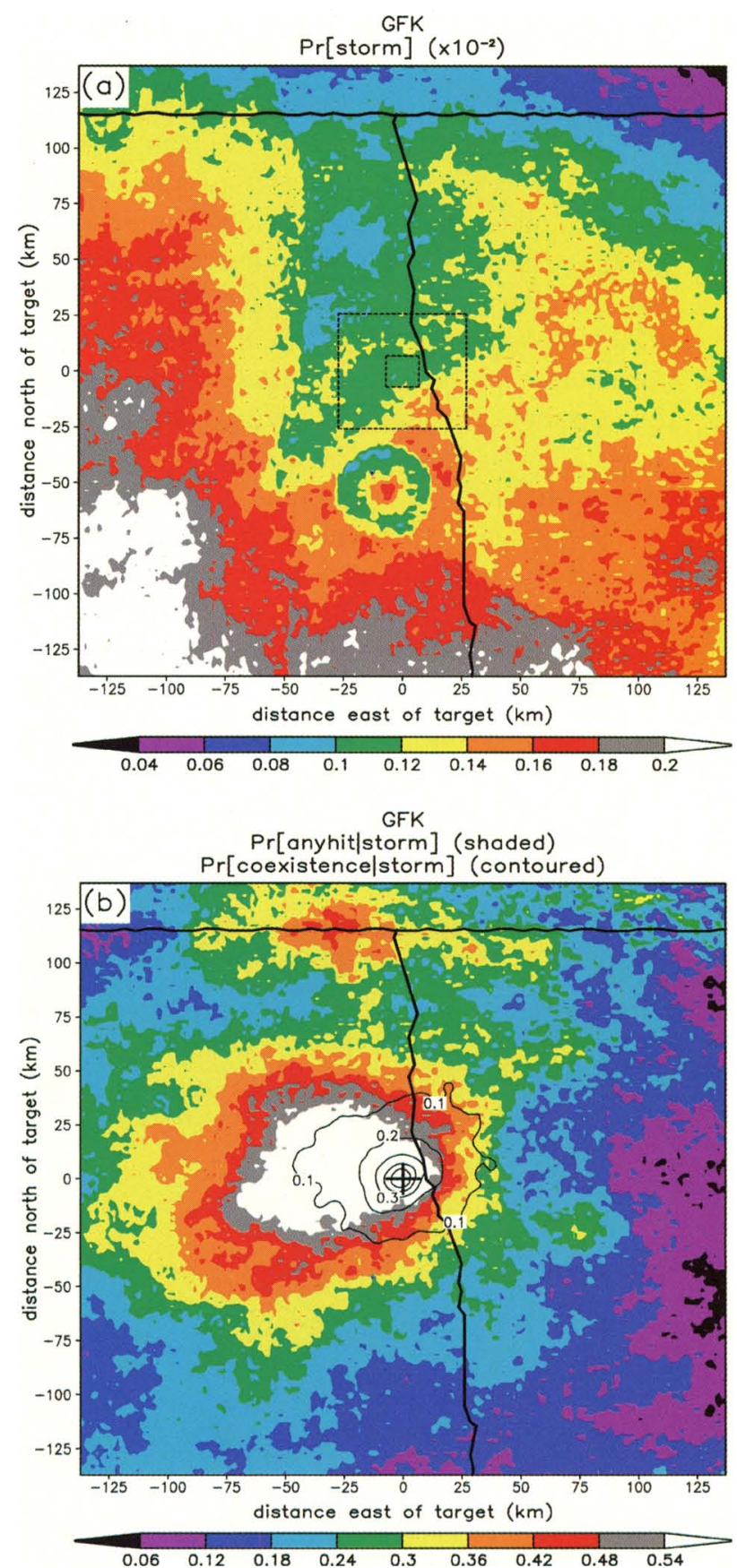

FIG. 9. Same as in Fig. 7, except for GFK. Note that the shading scales differ from those in Fig. 7. The mean areal values of $\mathrm{Pr}_{\text {storm }}$ were as follows: city, $\mathrm{O} . \mathrm{I} \mathrm{I} \mathrm{I} \times \mathrm{I} \mathrm{O}^{-2}$; county, $0.120 \times 10^{-2}$; and CWA, $0.135 \times 10^{-2}$. The $100-\mathrm{km}$ average $\mathbf{P r}_{\text {anyhit|storm }}$ value was $\mathbf{0 . 3 3}$. 
pared to points farther east and west. The actual value of GFK's $\mathrm{Pr}_{\text {storm }}$ was $0.111 \times 10^{-2}$, making it $18.4 \%$ lower than that of the surrounding CWA and placing it in the bottom quartile (Fig. 3). On average, each year GFK experienced less than $10 \mathrm{~h}$ of storminess. The strongest east-west gradient in $\mathrm{Pr}_{\text {storm }}$ was approximately 50-60 km west of GFK, and this corresponds to the western wall of the Red River Valley of the North and the former bed of Glacial Lake Agassiz, in which Grand Forks is centered (Fig. 10). Because the gradients in elevation and in $\mathrm{Pr}_{\text {storm }}$ correspond so well, we infer that the Red River Valley is comparatively inhospitable to thunderstorms, perhaps because of local solenoidal circulations induced by the terrain. Notably, the gradient in $\mathrm{Pr}_{\text {storm }}$ west of GFK (Fig. 9a) also roughly coincides with the eastern edge of the Minot, North Dakota, WSR-88D radar range. We comment on this sort of signal further in the appendix. However, the gradient to the east of GFK does not correspond to any such change in radar coverage, hence, the GFK signal appears to be at least partly physical.

Also defining GFK as a hole were its relatively low values of $\mathrm{Pr}_{\text {anyhit|storm }}$ (Fig. 9b). A comparison of GFK's $\mathrm{Pr}_{\text {anyhitstorm }}$ to LNK's (Fig. 7b) and to those of the good population (Fig. 8b) illustrates that although thunderstorms only a few tens of kilometers west of GFK were followed by storms at the target at typical rates, storms rarely hit GFK from any other direction. This large directionality in $\mathrm{Pr}_{\text {anyhit|storm }}$ (Fig. 4c) led to the small azi-

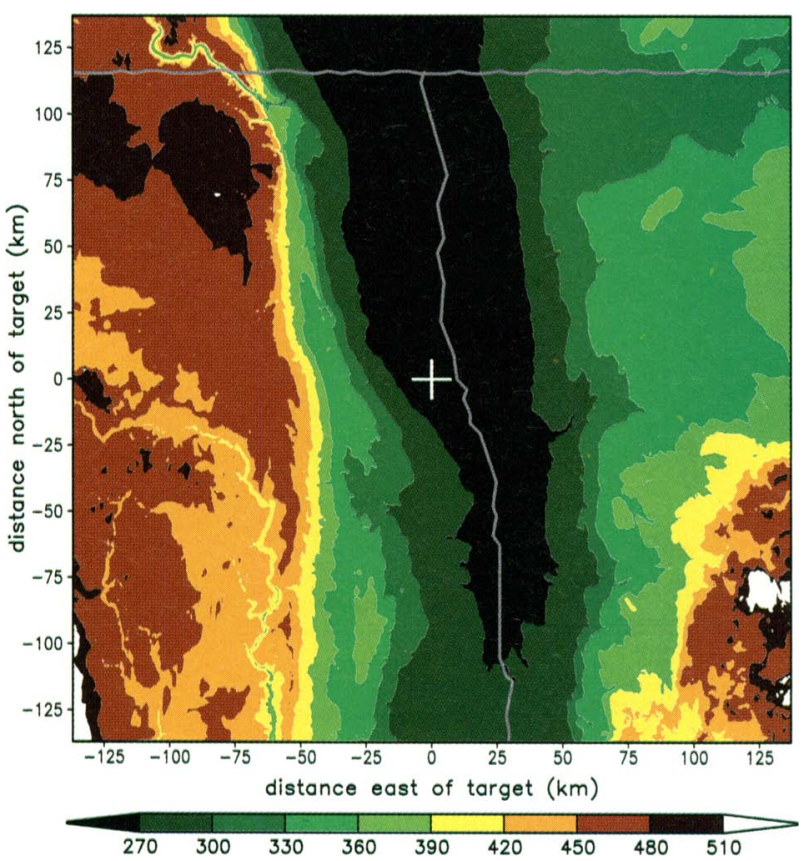

Fig. I0. Elevation (m) of topography near GFK (marked by white cross). muthally averaged values for $\mathrm{Pr}_{\text {anyhitstorm }}$ at GFK (Fig. 4a) and to its qualification as a hole.

Reasons for the isolated, secondary maximum in $\mathrm{Pr}_{\text {anyhit|storm }}$ at $x=-30 \mathrm{~km}, y=120 \mathrm{~km}$ (Fig. 9b) are unclear. Storms were so scarce there (Fig. 9a) that the signal in $\mathrm{Pr}_{\text {anyhit|storm }}$ may be attributable to only a few occasions on which storms in the secondary maximum occurred serendipitously within $2 \mathrm{~h}$ of storms at GFK, without traversing the intervening $100 \mathrm{~km}$. This is consistent with the notion that storminess was comparatively isolated in the GFK region (storms appeared to have been quite circular at GFK; Fig. 4d) and covered an area somewhat smaller than average (GFK's storm area statistic was $953 \mathrm{~km}^{2}$; cf. Fig. 5b). This implies a smaller proportion of storminess due to fronts and linear convective systems. When episodes of organized precipitation are rare in a region, it is not surprising that the region's storm statistics compare unfavorably with those from most other sites.

A weather hot spot. The lone hot spot among the 28 meteorologic targets was TLH (Fig. 11). In TLH's CWA, values of $\mathrm{Pr}_{\text {storm }}$ decreased southward and were largest roughly $20 \mathrm{~km}$ inland from the coast. TLH lies on the northern fringe of these maxima, which were almost certainly caused by recurring diurnal convection associated with the sea-breeze front (e.g., Byers and Rodebush 1948; Frank et al. 1967). The $\mathrm{Pr}_{\text {storm }}$ decreased farther inland, especially to the northeast. As a result, it is evident from Fig. 11a that TLH's county (and city) mean $\mathrm{Pr}_{\text {storm }}$ was relatively high compared to values in many other parts of the CWA. The actual value for TLH's county was $0.709 \times 10^{-2}$, making it $8.4 \%$ higher than that of the surrounding CWA and placing it in the top quartile (Fig. 3). For this reason, TLH qualified as a potential weather hot spot. TLH's county had the highest mean value for $\mathrm{Pr}_{\text {storm }}$ of any target's county in this study, including the random targets. Every year, TLH experienced roughly $62 \mathrm{~h}$ of storminess. The maxima in $\mathrm{Pr}_{\text {storm }}$ south and southeast of TLH illustrate an important point (Fig. 11a). Hot spots need not have been the single most frequent sites of thunderstorms in their CWA areas. Although TLH was a hot spot, other locations in its CWA were even stormier.

TLH's regional plot of $\mathrm{Pr}_{\text {anyhitstorm }}$ (Fig. 11b) is in many ways similar to that for the typical site, LNK (Fig. 7b). The major axes of maxima in $\mathrm{Pr}_{\text {anyhitstorm }}$ were oriented southwest to northeast, for example. The important difference is that, around TLH, high values of $\mathrm{Pr}_{\text {anyhit|storm }}$ covered a much larger azimuthal range. This is apparently because storms, or groups of storms, over TLH had comparatively large footprints (Fig. 5b), and 

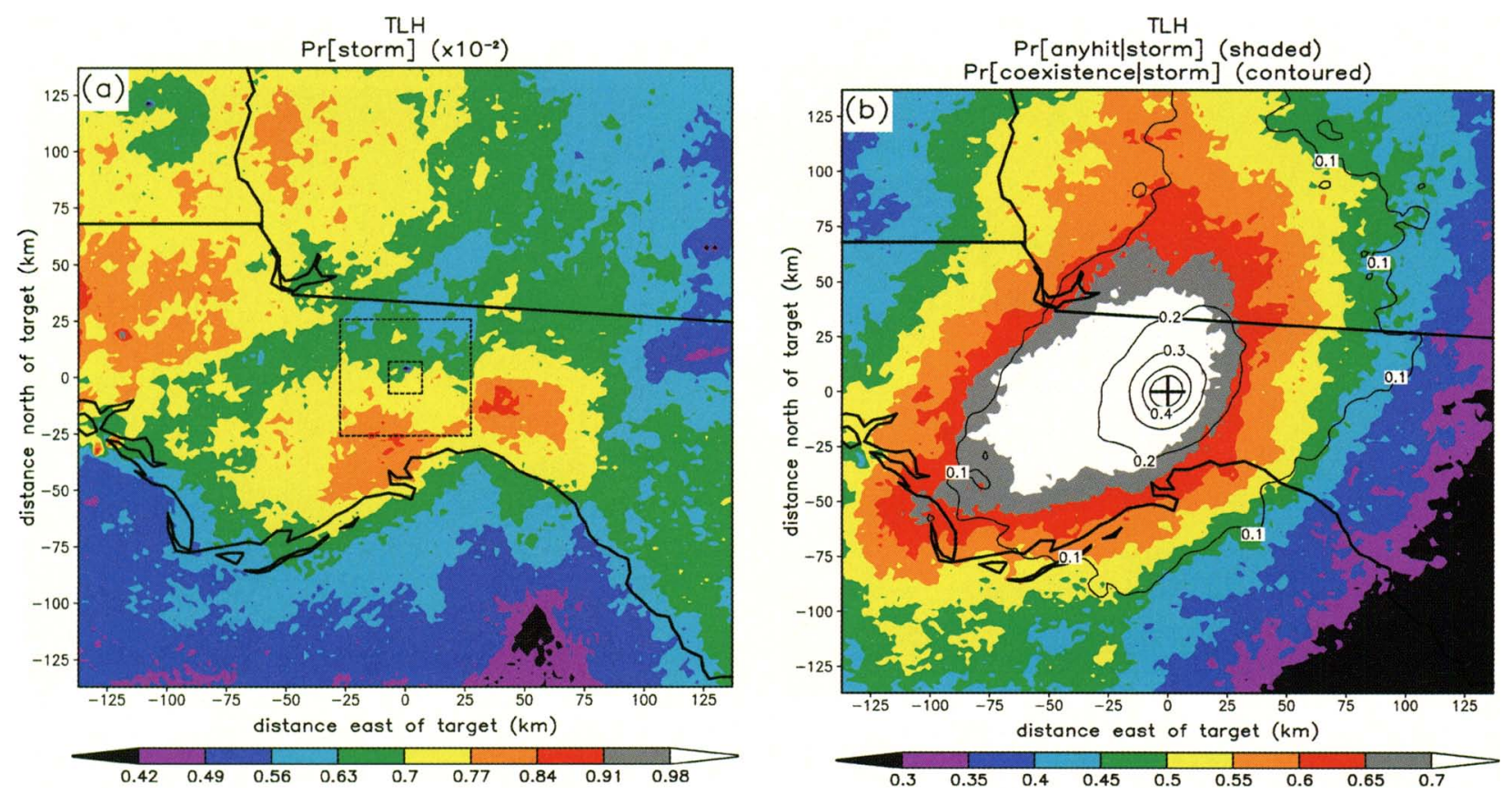

FIG. I I. Same as in Fig. 7, except for TLH. Note that the shading scales differ from those in Fig. 7. The mean areal values of $\mathrm{Pr}_{\text {storm }}$ were as follows: city, $0.692 \times 10^{-2}$; county, $0.709 \times 10^{-2}$; and CWA, $0.654 \times 10^{-2}$. The $100-\mathrm{km}^{-1}$ average $\mathbf{P r}_{\text {anyhit|storm }}$ value was $\mathbf{0 . 6 0}$.

yet had very small directionality in $\mathrm{Pr}_{\text {anyhit storm }}$ (Fig. 4c). In other words, consistent with the persistent sea breeze front, and the generally widespread thunderstorms that typify summer weather in Florida (e.g., Byers and Rodebush 1948), large groups of storms arrived at TLH from almost all directions. As a result of this, TLH's $100-\mathrm{km}$ average $\operatorname{Pr}_{\text {anyhit|storm }}$ was in the upper quartile of good targets (Fig. 4a), which helps establish TLH as a hot spot. The area over which $\operatorname{Pr}_{\text {anyhitstorm }} \geq 0.5$ for TLH was third largest among the 55 good points and over twice the median value (Fig. 5a). Although TLH and MIA both had very high $\operatorname{Pr}_{\text {storm }}$ values and might be expected to be similar, TLH may have been more like a hot spot because it was more heavily influenced by cool-season midlatitude fronts (being roughly $5^{\circ}$ farther north). This would explain its more elongated, larger footprint of storminess (cf. Figs. $4 \mathrm{~d}$ and $5 \mathrm{~b}$ ), and hence its greater regional $\mathrm{Pr}_{\text {anyhit|storm }}$ and lagged correlation in $\mathrm{dBZ}$.

Our assessment of TLH as a hot spot for convective weather is interesting given the claim by Lericos et al. (2002, p. 21) that "meteorologists ... have often observed the apparent demise of nonsupercell squall lines as they approach the Tallahassee area." Because our methods did not separate convective modes, it is possible that if only squall lines were considered, TLH was a weather hole. It is also possible that, although TLH was a hot spot according to our criteria, meteorologists' attention is often drawn to the coast southeast and southwest of TLH, where thunderstorms are even more frequent (Fig. 11a).

Interannual variability. Not only did distributions of thunderstorms vary spatially among targets, the distributions also varied temporally among years. The variations were no doubt partly a response to changes in regimes of the synoptic and planetary flows that shape the frequency and organization of convection. The interannual variability in the data is one measure of the robustness of our results.

LNK's two most outlying years (1996 and 2000) serve as useful examples. Although a typical site overall, LNK was a hot spot in 1996 according to our criteria for the 6-yr dataset. (The criteria would have been different for individual years.) LNK's $\mathrm{Pr}_{\text {storm }}$ was higher than that of areas to its southwest, west, northwest, north, and northeast (Fig. 12a), and the city was hit by a fairly high proportion of upstream storms (cf. Figs. 7b and $12 \mathrm{~b}$ ), especially from the west and southwest. In 2000, LNK was very nearly a hole according to our criteria for the 6-yr dataset. The city's $\mathrm{Pr}_{\text {storm }}$ was lower than in much of its CWA (e.g., the quasi-annular ring of elevated $\mathrm{Pr}_{\text {storm }}$ at a radius of approximately $100 \mathrm{~km}$ in Fig. 13a), and LNK had quite low upstream values of $\mathrm{Pr}_{\text {anyhit|storm }}$ in nearly all directions (cf. Figs. $7 \mathrm{~b}$ and 13b). In three of the four other years, LNK was neither a hot spot nor a hole and had statistics more similar to the means listed in Fig. 7. In 2002, LNK was a hot spot. 

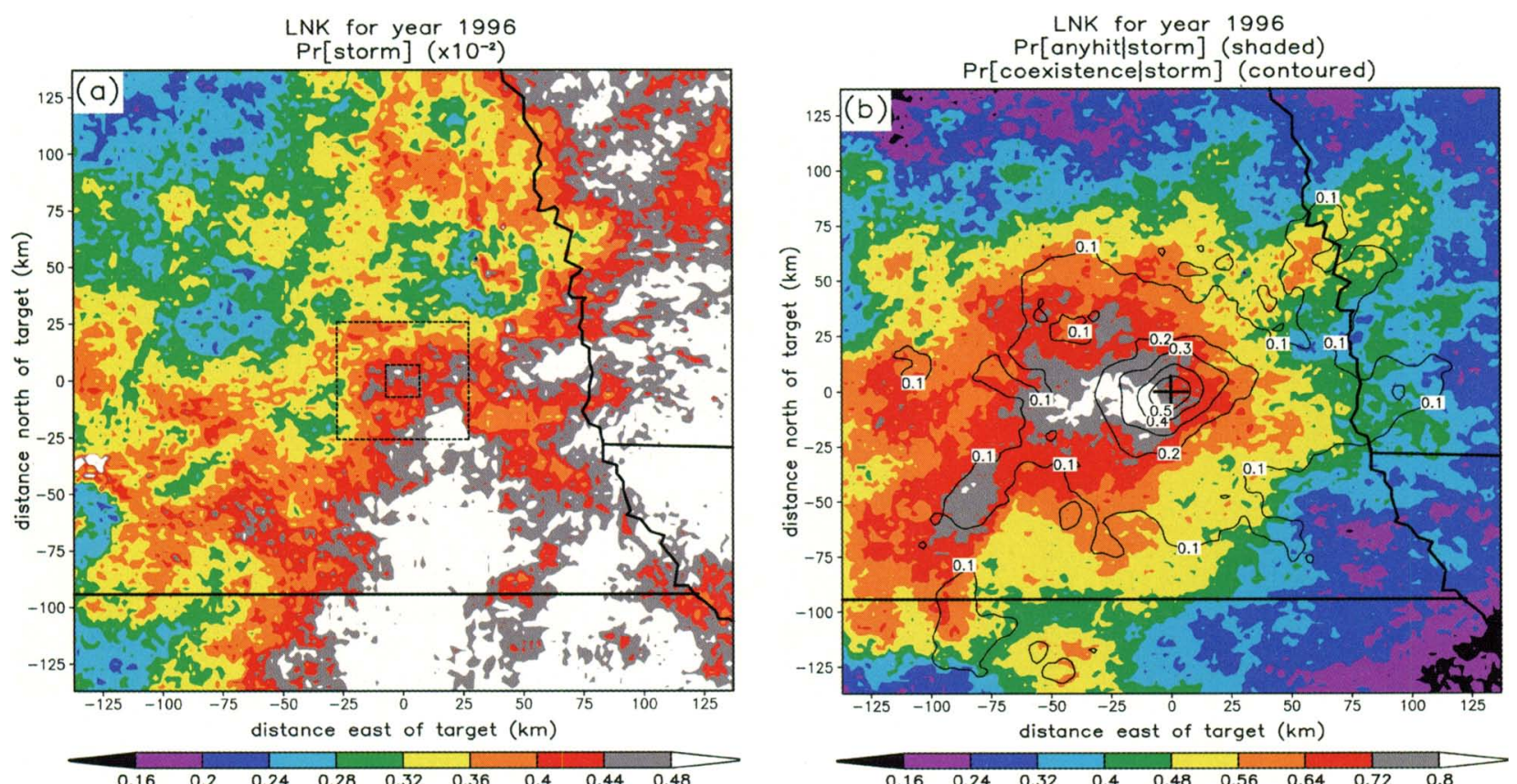

FIG. 12. Same as in Fig. 7, except only including data from 1996, the year in which LNK was most like a thunderstorm hot spot. The mean areal values of $\mathrm{Pr}_{\text {storm }}$ were as follows: city, $0.435 \times 10^{-2}$; county, $0.411 \times 10^{-2}$; CWA, $0.395 \times 10^{-2}$. The 100-km average $\mathbf{P r}_{\text {anyhitststorm }}$ value was 0.55 .
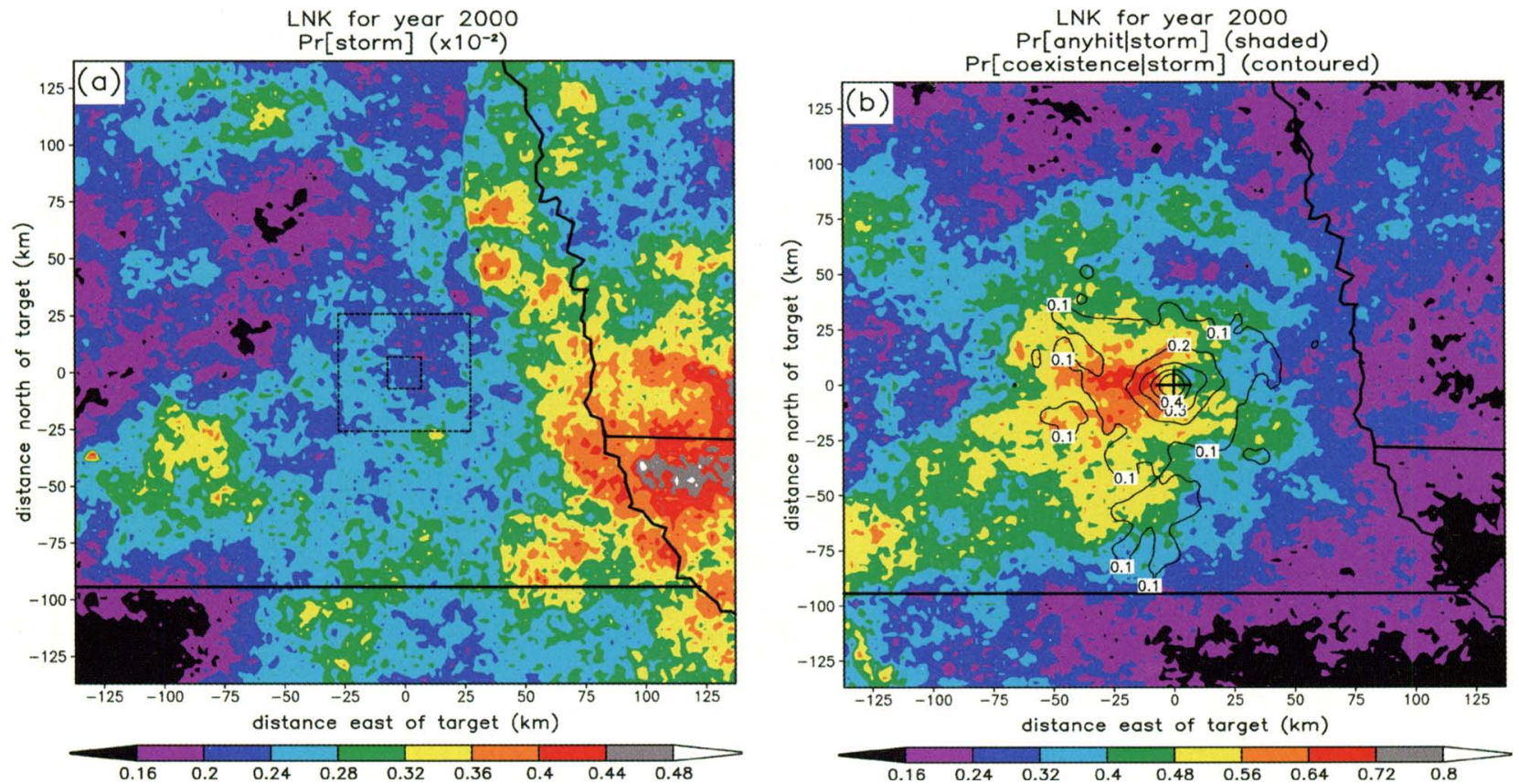

Fig. 13. Same as in Fig. 7, except only including data from 2000, the year in which LNK was most like a thunderstorm hole. The mean areal values of $\mathrm{Pr}_{\text {storm }}$ were as follows: city, $0.225 \times 10^{-2}$; county, $0.240 \times 10^{-2}$; and CWA, $0.264 \times 10^{-2}$. The 100-km average $\operatorname{Pr}_{\text {anyhit|storm }}$ value was 0.38 .

GFK, a hole overall, had lower values of $\operatorname{Pr}_{\text {storm }}$ than that of its surrounding CWA in five of the six years and would have qualified as a hole (including the $\mathrm{Pr}_{\text {anyhitstorm }}$ criterion) in four of the six years. GFK was never a hot spot. TLH, a hot spot overall, had higher values for $\mathrm{Pr}_{\text {storm }}$ than that of its surrounding CWA in five of the six years, would have qualified as a strong hot spot in one of the six years, and very nearly qualified in three additional years. TLH was never a hole. 
In short, the regional distribution and behavior of thunderstorms at the targets varied from year to year, such that many were hot spots or holes at certain times. However, for the $6 \mathrm{yr}$ we studied, extreme periods evened out for most such targets. Only for those that qualified as holes and hot spots, GFK and TLH, did extreme distributions of thunderstorms tend to persist from year to year. Admittedly, a 6-yr dataset is relatively short for a thunderstorm climatography, as most targets' interannual variability suggests, and our results should be regarded in this context.

So, do meteorologists suppress thunderstorms? If meteorologists suppress thunderstorms, weather holes would have been more common among the good meteorologic targets than among the good random targets. They were not. Given our method, at most it would have been possible to find 13 holes and 13 hot spots among the 55 good targets. An even distribution would then have yielded 3.8 holes and 3.8 hot spots among the meteorological targets, and 9.2 holes and 9.2 hot spots among the random targets. Instead, we found just one meteorological hole and one meteorologic hot spot, along with eight random holes and four random hot spots. In other words, holes and hot spots were less common than might be expected, and were decidedly uncommon among meteorological communities. Many of the meteorological targets exhibited some hole- or hot spot-like qualities, but overall they fell fairly close to the typical values for all of the points that we tested.

SUMMARY AND INTERPRETATION. Driven by curiosity and skepticism, we tested the frequent assertion that meteorologists and weather enthusiasts live in weather holes-that is, places that receive less exciting weather than do their surroundings. We look upon this widespread superstition as an opportunity to take a small step toward improved understanding of the statistical behavior of moist convection.

Our analyses incorporated NOWrad ${ }^{\text {Th }}$ national composites, or summaries, of WSR-88D reflectivity data for 6 yr: 1996-2000 and 2002. We selected 28 target cities, based on their prominent meteorological communities, and 50 random targets. We then defined a storm element (or, more briefly, a storm) as an echo of $\geq 40 \mathrm{dBZ}$ and calculated various statistics, from which we defined two criteria for a weather hole. A hole must have had markedly fewer storms than its surroundings during the six years we studied, and it must have been disproportionately missed by approaching storms. The converse criteria defined a hot spot.
According to our data and methods, a meteorologist's hometown is no more likely to be a weather hole or hot spot than is any random place around the conterminous United States. During the entire $6 \mathrm{yr}$ period, the lone weather hole was Grand Forks, North Dakota, and the lone hot spot was Tallahassee, Florida. During any single year, many of the targets were holes or hot spots according to at least one criterion but such short-term behavior does not justify meteorologists' enduring superstitions that the most exciting weather consistently misses them. Over time, very few sites were repeatedly, anomalously missed or hit by storms.

This study is by no means definitive. It is impossible to choose objective definitions of a hole or hot spot that are not also somewhat arbitrary. Other equally reasonable definitions might yield slightly different results. For example, a reviewer jokingly lamented being "missed by the 'best' storms 'on all sides" and pointed out that some location might be hit by a storm (echo $\geq 40 \mathrm{~dB} Z$ ) but still be missed by even stronger echoes that were upstream or nearby. The time-lagged correlation in $\mathrm{dBZ}$ actually does address this and similar situations, and it is highly correlated to the $\mathrm{Pr}_{\text {anyhittstorm }}$ statistic (a correlation of 0.78). So, the $40-\mathrm{dBZ}$ threshold appears to be a solid reference point for the present discussion, even though there remain other methods for constructing climatographies that may yield additional insight into the statistical behavior of convective storms.

This study is also not completely categorical because the WSR-88D network, although a boon to researchers and forecasters, is still an imperfect tool for diagnosing storms (see the appendix). The network is too sparse, especially in the western United States, and terrain can perpetually hide storms in certain regions, even when a radar is nearby. Small amounts of ground clutter seem to elude quality controls, and poor calibration and the range dependence of reflectivity can introduce into climatographies persistent features that are extremely difficult to eradicate. In some sense, though, these imperfections are unimportant for our specific application, because the fairest evaluation of superstitions about weather holes and hot spots is a test of the very dataset that seems to inspire such superstitions: radar reflectivity. Most of the persistent holes or hot spots in reflectivity that meteorologists believe to plague their hometowns, whether physical or artificial, simply did not appear in our analyses.

In part, the commonly held belief in weather holes seems to stem from a generally poor understanding of the statistical behavior of moist convection. Significantly, beyond its usefulness in addressing thun- 
derstorm holes and hot spots, a large radar reflectivity dataset allowed us to characterize the typical sizes, shapes, orientations, and temporal behaviors of storms, or groups of storms, in various parts of the country. To the extent that our limited study is representative of long-term storminess in the conterminous United States as a whole, our results suggest that typical storms are likely to be somewhat elongated, emphasizing the major role played by fronts and linear convective systems; are likely to approach a location from climatically favored directions less than half of the time; and, when within $100 \mathrm{~km}$, are likely to actually strike a given location less than half of the time. Departures from these median statistics then may help explain unique storm behaviors in certain regions, such as the Red River Valley of the North (GFK) or southern Florida (MIA).

The data and methods we used together are one step toward understanding anecdotal claims about weather holes and hot spots. More generally, and much more importantly, such data and methods may also prove to be very powerful tools for forecasting thunderstorms and for quantifying the risks that thunderstorms pose to society. For many decades, researchers have proposed and sometimes demonstrated that climatic statistics can be a valuable tool for meteorological and hydrological forecasting (e.g., Kincer 1916; Reap and Foster 1979; Balling 1985; Matthews and Geerts 1995; Krzysztofowicz and Sigrest 1997). An example of a successful application of this sort is Model Output Statistics (MOS), in which statistics from observations and from deterministic NWP models are combined. In decades past, efforts to apply radarderived statistics to forecasts of thunderstorms were sometimes problematic. For example, there were signs that poor calibration and variations among operators produced systematic biases in reflectivity from one radar to another (Weiss et al. 1980), and no automated, national system existed for collecting and processing the data. The WSR-88D network is a great improvement over earlier radars, notwithstanding imperfections such as those mentioned above (and in the appendix).

As computational resources permit, it should prove useful to perform these and other statistical analyses for every point in the WSR-88D domain, in order to assess possible links between storms and local- to regional-scale terrain and land cover features. Every day, WSR-88D databases get larger. As they do, the statistical significance of the patterns in even small subsets of the data also gets larger. In the future, it should be possible to construct probabilistic, short-term forecasts of thunderstorm evolution and motion by using previous storms as analogues. In addition, a sufficiently large database should allow us to stratify statistical forecasts by factors such as time of year, time of day, climatic index, synoptic wind pattern, and soil moisture.

Currently, forecasters can use a few minutes of realtime radar data to track thunderstorms and predict their locations. Perhaps before long, forecasters might use decades of historical radar data not only to track extant cells, but also to predict changes in those cells' strengths and motions as well as to predict where new cells will develop. Indeed, an informal feasibility study into precisely this capability is now underway at the $\mathrm{Na}$ tional Center for Atmospheric Research. We will follow their progress with great anticipation.

ACKNOWLEDGEMENTS. NOWrad "w" national radar composite data were provided by the Global Hydrology Resource Center. NOWrad ${ }^{\text {m }}$ is a registered trademark of the Weather Services International (WSI) Corporation. We appreciate comments and assistance from D. Ahijevych, W. Callahan, R. Carbone, L. Carey, C. Davis, R. Edwards, J. Gourley, R. Henson, S. Honey, T. Lane, D. Loope, R. Maddox, D. Pederson, E. Pytlak, C. Rowe, D. Thompson, R. Thompson, D. Zaras, and two anonymous reviewers, whose insightful suggestions greatly improved the manuscript.

\section{APPENDIX: IMPERFECTIONS IN RADAR} DATA. Coverage and range dependence. Although the WSR-88D network provides unprecedented radar coverage of the conterminous United States, the coverage is still incomplete, especially in the western third of the nation, where it is impossible to construct reliable thunderstorm climatographies on any scale except the local (Fig. A1). The incompleteness of the radar network is reflected in some of the statistics we calculated, particularly in $\operatorname{Pr}_{\text {storm }}$ (Fig. 6). The fewer radars that scan over a target, the less likely such coarse sampling will observe small pockets of high reflectivity. It may not simply be coincidental that the lone weather hole in our dataset, GFK, is covered by only one radar, and the lone hot spot, TLH, is covered by many (Fig. A1).

This problem is compounded if the radars are far from a target because a radar's sensitivity is a function of distance to a target. Reflectivity depends on range partly because a tilted radar beam's altitude depends on range. Thus, certain angles of tilt intersect the melting level and hence produce bright bands at certain ranges (Baeck and Smith 1998), and may also over- or undershoot storms' regions of maximum reflectivity. Reflectivity also depends on range because radar sample volumes are larger at 
greater distances from a radar, thereby failing to resolve small reflectivity maxima. It is more likely that a reflectivity threshold will be exceeded near a radar, where there are many small volumes, than far from a radar, where there are but a few large volumes. Although these problems of coverage and range were unavoidable, our 40-dBZ storm threshold was seemingly less susceptible to them than were lower reflectivity thresholds (cf. Figs. A1 and A2).

\section{Ground clutter and blocking by} terrain. In the domains used for analysis, there are several pixels whose anomalous values revealed the presence of persistent clutter (e.g., by

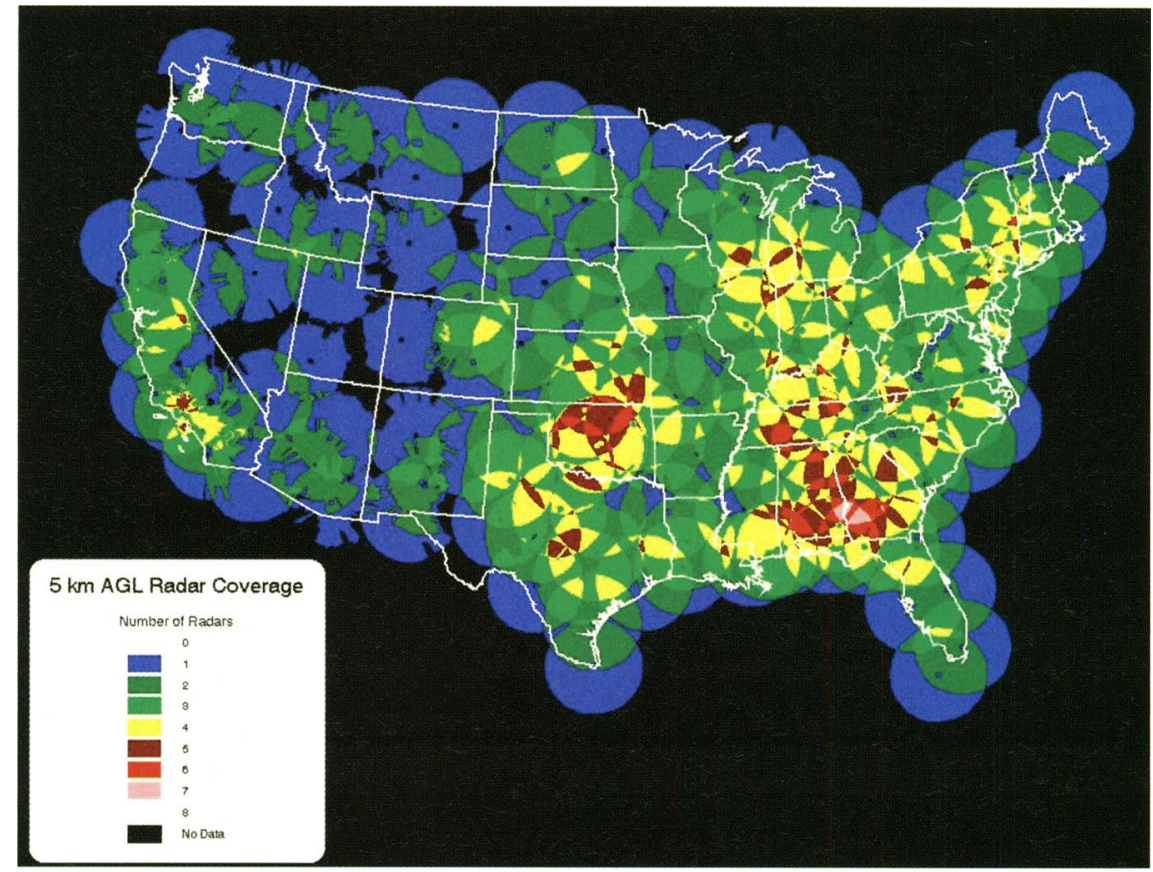

FIG. Al. Coverage of WSR-88D radar beams at $5 \mathrm{~km}$ (AGL) over the conterminous United States, following the method of Maddox et al. (2002). Figure kindly provided by J. J. Gourley, National Severe Storms Laboratory, Norman, Oklahoma. a telecommunications an-

tenna near a radar), even though WSI's quality control of the NOWrad ${ }^{\mathrm{m}}$ data includes automatic, then manual, removal of most ground clutter. Excluding these pixels had very little effect on the statistics, which were averaged over areas much larger than one pixel.

Beam blocking by complex terrain was much more problematic. Statistics for TUS are an exemplary case (Fig. A3). The primary regional radar for the TUS area is on high ground roughly $40 \mathrm{~km}$ southeast of the target (Fig. A4). The radar beam is relatively unimpeded in its observations directly over TUS, the Santa Catalina Mountains to the north-northeast of TUS, and high terrain farther to the north and northwest (Fig. A3). However, the beam is mostly blocked by the Santa Rita Mountains to the radar's southwest, the Rincon Mountains to its northeast, and the Whetstone and Dragoon Mountains to its east and southeast (cf. Figs. A3 and A4).

This beam blocking presented us with several obvious difficulties. For example, it is unclear whether regions of very high $\operatorname{Pr}_{\text {storm }}$ (e.g., at $x=15 \mathrm{~km}, y=30 \mathrm{~km}$ in Fig. A3) corresponded to virtually stationary orographic thunderstorms or to ground returns from terrain, although the high gradients around the local minima in $\operatorname{Pr}_{\text {anyhitstorm }}$ at the same places suggest the latter (Fig. A3). Second, owing to beam blockage, there is no information in the lee of the nearby ranges (as discussed above), so that comparing TUS's $\mathrm{Pr}_{\text {storm }}$ with that of its CWA has very little meaning. Third, owing to the paucity of thunderstorm echoes, $\mathrm{Pr}_{\text {anyhitstorm }}$ in the radar voids was excessively noisy and unreliable, especially in the southwestern part of the Tucson CWA (Fig. A3). For these reasons, although we gained some limited insight into the regional behavior of thunderstorms at targets with poor radar coverage, we excluded them from our core analyses.

Calibration. A WSR-88D that is not well-calibrated can over- or undermeasure reflectivity compared to other nearby radars in the network. Figure 6 illustrates the effect poor calibration can have on $\mathrm{Pr}_{\text {storm }}$. The circle of high values centered on Wilmington in southern North Carolina is an obvious signature of an overcalibrated, or "hot," radar. Certain configurations of cold (undercalibrated) and hot radars may have artificially produced the sorts of gradients, maxima, and minima in $\operatorname{Pr}_{\text {storm }}$ that we used in our first criterion for defining weather holes and hot spots. Hot and cold radars may also have masked real holes and hot spots. However, as with coverage and range, this problem seemed to be mitigated somewhat by our choice of the $40-\mathrm{dBZ}$ storm threshold (Fig. A2). Nevertheless, concern over these effects is partly what motivated us to adopt the second criterion for holes and hot spots, that based on $\mathrm{Pr}_{\text {anyhit|storm, }}$ which is less sensitive to poor radar calibration. 

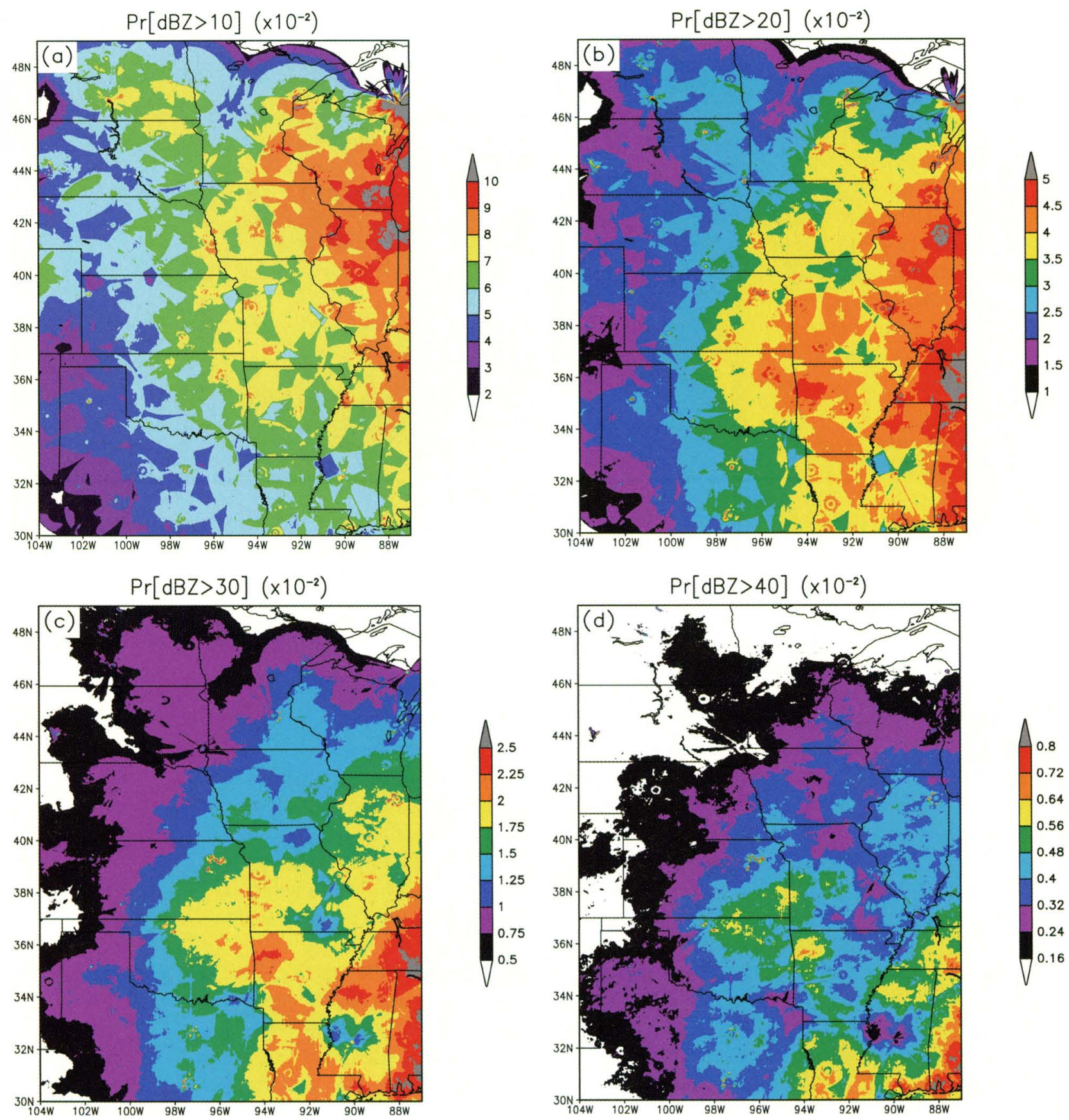

FIG. A2. Frequency of echoes exceeding (a) 10, (b) 20, (c) 30, and (d) $40 \mathrm{dBZ}$ for the central United States. Values have been multiplied by 100 (and therefore are equivalent to percentages) and are scaled as shown in each color bar.

\section{REFERENCES}

Alexander, W. H., 1915: Distribution of thunderstorms in the United States. Mon. Wea. Rev., 43, 322-340.

Baeck, M. L., and J. A. Smith, 1998: Rainfall estimation by the WSR-88D for heavy rainfall events. Wea. Forecasting, 13, 416-436.

Balling, R. C., Jr., 1985: Warm season nocturnal precipitation in the Great Plains of the United States. J. Climate Appl. Meteor., 24, 1383-1387.
Banta, R. M., 1990: The role of mountain flows in making clouds. Atmospheric Processes over Complex Terrain, Meteor. Monogr., No. 45, Amer. Meteor. Soc., 229-283.

—, and C. B. Schaaf, 1987: Thunderstorm genesis zones in the Colorado Rocky Mountains as determined by traceback of geosynchronous satellite images. Mon. Wea. Rev., 115, 463-277.

Biggerstaff, M. I., and R. A. Houze Jr., 1993: Kinematics and microphysics of the transition zone of the 

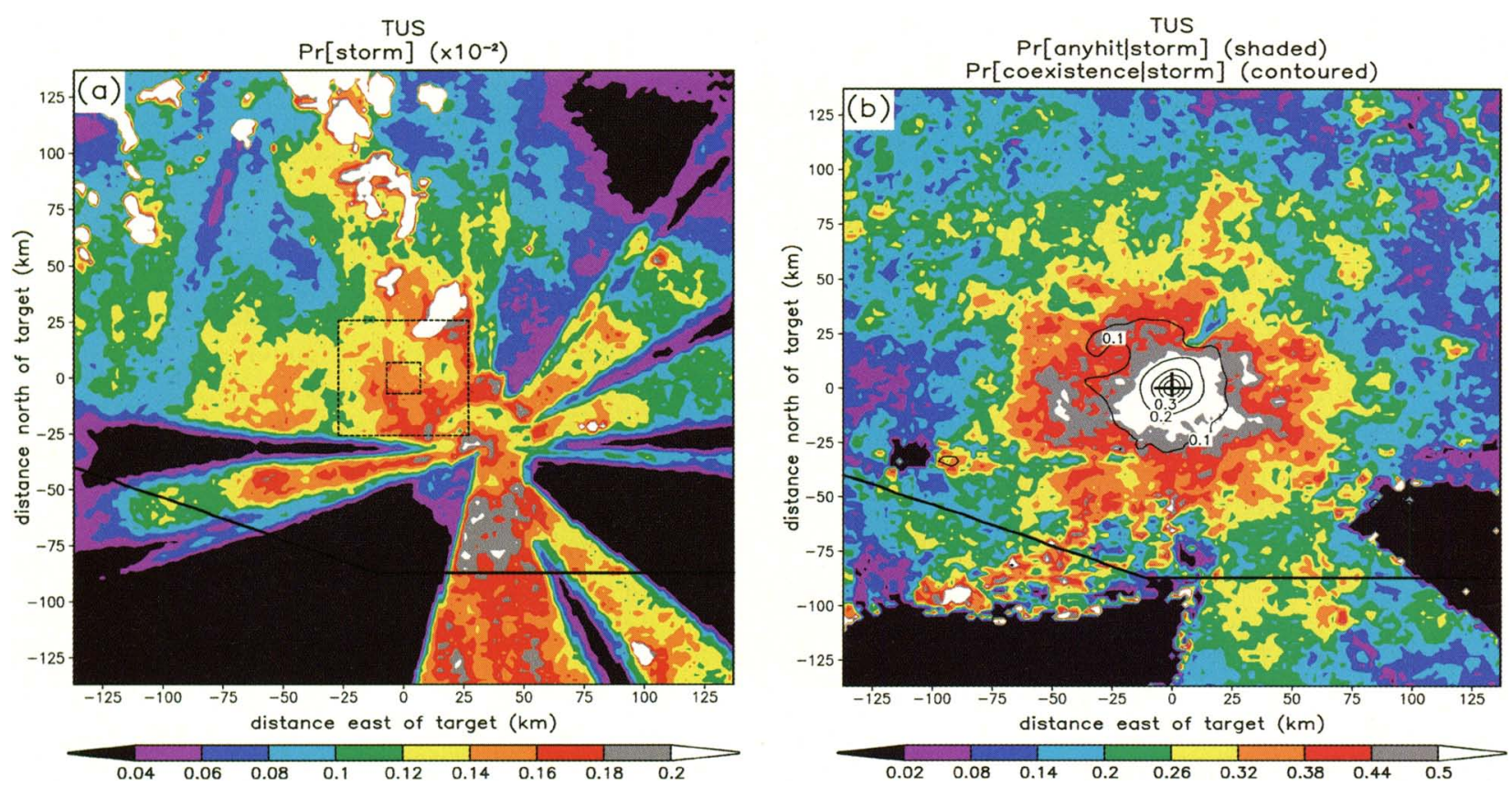

FIG. A3. Same as in Fig. 7, except for TUS. Note that the shading scales differ from those in Fig. 7. The mean areal values of $\mathrm{Pr}_{\text {storm }}$ were as follows: city, $0.149 \times 10^{-2}$; county, $0.165 \times 10^{-2}$; and CWA, $0.099 \times 10^{-2}$. The $100-\mathrm{km}$ average $\mathrm{Pr}_{\text {anyhit|storm }}$ value was $\mathbf{0 . 3 0}$.

10-11 June 1985 squall line. J Atmos. Sci., 50, 3091-3110.

Boccippio, D. J., K. L. Cummins, H. J. Christian, and S. J. Goodman, 2001: Combined satellite- and surfacebased estimation of the intracloud-cloud-toground lightning ratio over the continental United States. Mon. Wea. Rev., 129, 108-129.

Byers, H. R., and R. R. Braham, 1949: The Thunderstorm. U.S. Department of Commerce, U.S. Weather Bureau, 287 pp.

— , and H. R. Rodebush, 1948: Causes of thunderstorms of the Florida peninsula. J. Meteor., 5, 275280.

Changery, M. J., 1981: National thunderstorm frequencies for the contiguous United States. U.S. Nuclear Regulatory Commission Tech. Rep. NUREG/CR2252, $22 \mathrm{pp}$.

Christian, H. J., and Coauthors, 1999: The Lightning Image Sensor. Proc. 11th Int. Conf. on Atmospheric Electricity, Guntersville, AL, ICAE, 726-729.

Court, A., and J. F. Griffiths, 1981: Thunderstorm climatology. Thunderstorm Morphology and Dynamics, E. Kessler, Ed., University of Oklahoma Press, 9-39. Dai, A., 2001a: Global precipitation and thunderstorm frequencies. Part I: Seasonal and interannual variations. J. Climate, 14, 1092-1111.

_ 2001b: Global precipitation and thunderstorm frequencies. Part II: Diurnal variations. J. Climate, 14, 1112-1128.

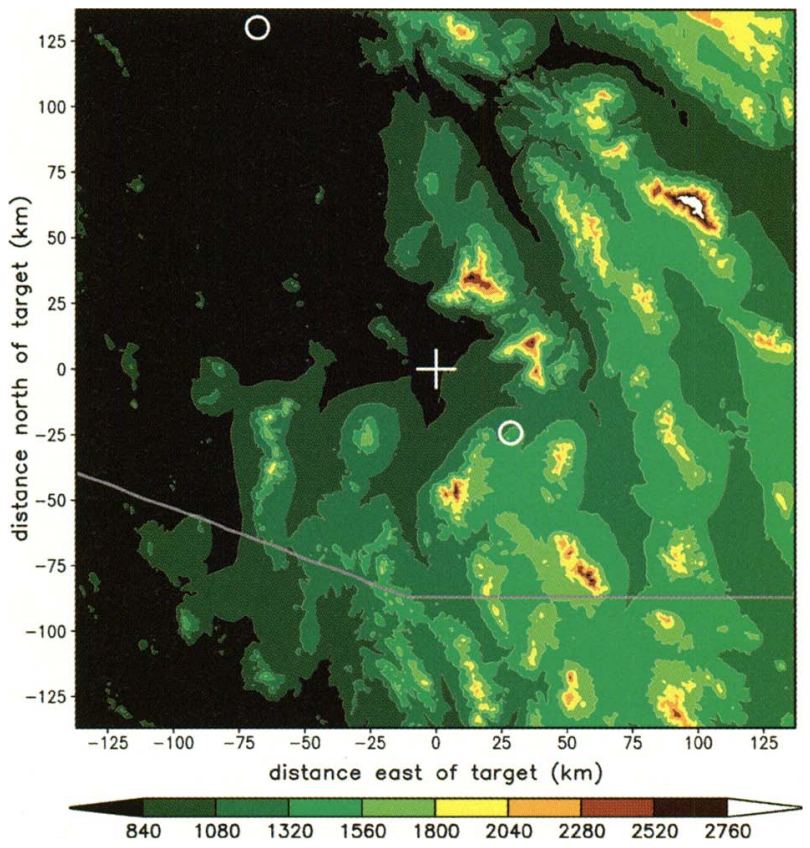

FIG. A4. Elevation (m) of topography near TUS (white cross). The white circles mark the Pima County/Tucson (southeast of TUS) and Mesa/Phoenix (north-northwest of TUS) WSR-88D radars.

Falconer, P. D., 1984: A radar-based climatology of thunderstorm days across New York state. J. Climate Appl. Meteor., 23, 1115-1120.

Fowler, W. B., and J. B. Helvey, 1974: Effect of largescale irrigation on climate in Columbia Basin. 
Science, 184, 121-127.

Frank, N. L., P. L. Moore, and G. E. Fisher, 1967: Summer shower distribution over the Florida peninsula as deduced from digitized radar data. J. Appl. Meteor., 6, 309-316.

Gamache, J. F., and R. A. Houze Jr., 1982: Mesoscale air motions associated with a tropical squall line. Mon. Wea. Rev., 110, 118-135.

Grazulis, T. P., 2001: The Tornado: Nature's Ultimate Windstorm. University of Oklahoma Press, $324 \mathrm{pp}$.

Hallenbeck, C., 1922: The topographic thunderstorm. Mon. Wea. Rev., 50, 284-287.

Harrington, M. W., 1894: Rainfall and snow of the United States. U.S. Weather Bureau Bulletin C, 80 pp.

Hindman, E. E., II, 1973: Air currents in a mountain valley deduced from the breakup of a stratus deck. Mon. Wea. Rev., 101, 195-200.

Humphreys, W. J., Ed., 1920: Physics of the Air. Franklin Institute, $665 \mathrm{pp}$.

Kincer, J. B., 1916: Daytime and nighttime precipitation and their economic significance. Mon. Wea. Rev., 44, 628-633.

Krzysztofowicz, R., and A. A. Sigrest, 1997: Local climate guidance for probabilistic quantitative precipitation forecasting. Mon. Wea. Rev., 125, 305-316.

Lericos, T. P., H. E. Fuelberg, A. I. Watson, and M. L. Weisman, 2002: The effects of coastlines on the evolution of strong, long-lived squall lines. Preprints, 21st Conf. on Severe Local Storms, San Antonio, TX, Amer. Meteor. Soc., 21-24.

MacKeen, P. L., and J. Zhang, 2000: Convective climatology for central Arizona during the 1999 monsoon. Postprints, Second Southwest Weather Symp., Tucson, AZ, NWS/COMET and University of Arizona, 64-67.

Maddox, R. A., J. Zhang, J. J. Gourley, and K. W. Howard, 2002: Weather radar coverage over the contiguous United States. Wea. Forecasting, 17, 927-934.

Matthews, C., and B. Geerts, 1995: Characteristic thunderstorm distribution in the Sydney area. Aust. Meteor. Mag., 44, 127-138.

Michaels, P. J., R. A. Pielke Sr., J. T. McQueen, and D. E. Sappington, 1987: Composite climatology of Florida summer thunderstorms. Mon. Wea. Rev., 115, 2781-2791.

Moore, N., and S. Rojstaczer, 2001: Irrigation-induced rainfall and the Great Plains. J. Appl. Meteor., 40, 1297-1309.

Orville, R. E., 1987: Cloud-to-ground lightning flash characteristics from June 1984 through May 1985. J. Geophys. Res., 92, 5640-5644.
-_, and G. R. Huffines, 2001: Cloud-to-ground lightning in the United States: NLDN results in the first decade, 1989-98. Mon. Wea. Rev., 129, 11791193.

Pielke, R. A., Sr., 1974: A three-dimensional numerical model of the sea breezes over south Florida. Mon. Wea. Rev., 102, 115-139.

- 2001: Influence of the spatial distribution of vegetation and soils on the prediction of cumulus convective rainfall. Rev. Geophys., 39, 151-177.

Reap, D. M., 1986: Evaluation of cloud-to-ground lightning data from the western United States for the 1983-84 summer seasons. J. Climate Appl. Meteor., 25, 785-799.

—, and D. S. Foster, 1979: Automated 12-36 hour probability forecasts of thunderstorms and severe local storms. J. Appl. Meteor., 18, 1304-1315.

— , and D. R. MacGorman, 1989: Cloud-to-ground lightning: Climatological characteristics and relationships to model fields, radar observations, and severe local storms. Mon. Wea. Rev., 117, 518-535.

Rickenbach, T. M., and S. A. Rutledge, 1998: Convection in TOGA COARE: Horizontal scale, morphology, and rainfall production. J. Atmos. Sci., 55, 27152729.

Segal, M., R. W. Arritt, J. Shen, C. Anderson, and M. Leuthold, 1997: On the clearing of cumulus clouds downwind from lakes. Mon. Wea. Rev., 125, 639-646.

Sobczyk, M., 2002: Legend fails to protect Fostoria. The Courier, Findlay, $\mathrm{OH}, 14$ November. [Available online at www.thecourier.com/issues/2002/Nov/ 111402.htm.]

Stidd, C. K., 1975: Irrigation increases rainfall? Science, 188, 279-280.

Wallace, J. M., 1975: Diurnal variations in precipitation and thunderstorm frequency over the conterminous United States. Mon. Wea. Rev., 103, 406419.

Weiss, S. J., C. A. Doswell II, and F. P. Ostby, 1980: Comments on "Automated 12-36 hour probability forecasts of thunderstorms and severe local storms." J. Appl. Meteor., 19, 1328-1333.

Wilks, D. S., 1995: Statistical Methods in the Atmospheric Sciences. Academic Press, 467 pp.

Wilson, J. W., 1977: Effect of Lake Ontario on precipitation. Mon. Wea. Rev., 105, 207-214.

Witt, A., M. D. Eilts, G. J. Stumpf, E. D. Mitchell, J. T. Johnson, and K. W. Thomas, 1998: Evaluating the performance of WSR-88D severe storm detection algorithms. Wea. Forecasting, 13, 513-518. 